\title{
La Función Social de las Cooperativas Vascas
}

\author{
The Social Function of the Basque Cooperatives \\ Hanka bat lurrean, beste bat airean? \\ Miguel de la Fuente Cosgaya*
}

\begin{abstract}
Resumen: El presente trabajo trata de responder a la cuestión de cuál es la función social de las cooperativas vascas. Para ello, se realiza un esbozo de la Historia del cooperativismo en Euskal Herria, algo todavía en construcción y debate. Se expondrán una serie de entrevistas a diferentes agentes del cooperativismo: socios cooperativistas de Mondragon, de Olatukoop y representantes de las instituciones, contrastándolas con los más recientes trabajos de la literatura académica. Las conclusiones respecto a todo este trabajo se centran en cuál es la comunidad que se beneficia de esa función social y qué identidad generan las cooperativas en el territorio.
\end{abstract}

Palabras clave: Cooperativas, Función social, Euskal Herria, Historia del cooperativismo, Identidad cooperativa.

\begin{abstract}
This work aims to solve the question about which is the social function of the Basque cooperatives. To this effect, firstly, it will be done a draft of the Basque Country Cooperatives' History, something that is neither built nor pacific on the forum. With this frame, there will be exposed some interviews with different agents of the Basque cooperatives, workers-partners of Mondragon, of Olatukoop and, also, the institutions. All this will be contrast with the most recent papers of the Academy. The conclusions of this work focus on the community benefited from this social function and what kind of identity the cooperatives generate on the territory.
\end{abstract}

Keywords: Cooperatives, Social Function, Basque Country, History of Cooperatives, Cooperative identity.

Claves Econlit: P13 Cooperative Enterprises, B55 Social Economics, N34 Europe: 1913-, Z13 Economic Sociology • Economic Anthropology • Language • Social and Economic Stratification.

\footnotetext{
* Correspondencia a/Corresponding author: Miguel de la Fuente Cosgaya. Estudiante - Miguel.delafuente02@gmail.com Cómo citar/How to cite: De la Fuente Cosgaya, Miguel (2020). "La Función Social de las Cooperativas Vascas», GIZAEKOA Revista Vasca de Economía Social, 17, 131-180. (https://doi.org/10.1387/gizaekoa.22230).

Recibido: 26/05/2020; aceptado: 09/06/2020. ISSN 1698-7446 - elSSN 2444-3107 / (c) 2020 UPV/EHU
} 


\section{Introducción}

El presente artículo trata de exponer las líneas generales y principales conclusiones de mi Trabajo Final del Máster en Economía Social y Solidaria. Durante la realización del Máster hemos recibido una amplia formación en cooperativas pero también han surgido algunas preguntas sin aparente respuesta. Esto ha hecho que se despierte un interés especial por responder de manera articulada a estas preguntas, cuyo resultado se ha plasmado en el presente artículo.

Por hacer justicia a nuestros anónimos inspiradores, la idea básica del trabajo tomó forma durante la lectura de una obra que será clave: «El Mito de Mondragón» de Sharryn Kasmir. En la misma, la antropóloga realizó su trabajo de campo en Arrasate sumergida en el universo de las cooperativas. En una de las asambleas recogió lo siguiente;

Un hombre del público gritó: «En las cooperativas deberiamos tener más derechos; está escrito que deberíamos tener más derechos humanos!"

La discusión giró hacia una consideración filosófica del sentido del cooperativismo. Un miembro del KT hizo las siguientes preguntas retóricas: "¿Qué son las cooperativas? ¿Cuáles son los objetivos de las cooperativas? ¿Las cooperativas, desde dónde se dirigen? Si antes hablaban del ser humano, ahora sólo hablan de beneficios.» (Kasmir, 1999, p. 213)

Siguiendo el hilo de las preguntas que se hacían esos socios trabajadores podemos vislumbrar como la definición de las cooperativas está más estructurada en parámetros jurídicos y económicos que en términos filosóficos o sociopolíticos. Por eso, esa pregunta ¿Qué son las cooperativas? no tiene una respuesta única o estandarizada en todos los contextos y épocas. Y más aún si nos preguntamos ¿Para qué sirven las cooperativas? o de una manera más desarrollada ¿Cuál es la función social de las cooperativas? El planteamiento de estos problemas nos hizo pensar en la conveniencia de un análisis más contextual y acotado a una realidad concreta: la de Euskal Herria. Es decir, partiremos de la base de que la función social no es un axioma universal, como podría ser el de una sociedad de capital en torno a generar lucro ${ }^{1}$. Y es, a partir de ese sano relativismo, desde donde comenzamos a hablar de la tarea social de las cooperativas vascas. En cada momento, desde cada cooperativa y cada persona socia trabajadora se ha de entender, confrontar y contestar a qué es la cooperativa y a qué fin sirve.

1 Aunque hay que decir que existe debate sobre si las cooperativas tienen o no ánimo de lucro. En base a este ello, «las posiciones doctrinales pueden resumirse en tres: cooperativa como asociación, como sociedad específica, o como sociedad mercantil» (Bengoetxea, 2016, p. 209). 
El artículo presente se estructura en torno a dos ejes: el contexto histórico y el trabajo de campo. Se ha preferido prescindir del marco teórico puesto que no deja de ser el resultado de una revisión bibliográfica de las cooperativas en la Historia Económica, basándonos principalmente en (Monzón, 2003), y del Derecho comparado, en la que destaca sobremanera lo relativo a la función social de las cooperativas en la Constitución de Italia vid. (Fici, 2015).

Salvando esto, planteamos el primer eje de una manera ambiciosa. Puesto que en la revisión bibliográfica no se ha encontrado una información completa y que sistematice un análisis histórico del movimiento cooperativista en Euskal Herria, trataremos de esbozar una línea historiográfica de las cooperativas vascas ${ }^{2}$. Incluso del cooperativismo mondragonés, del que "se han escrito muchas páginas sobre las claves del éxito", en el que «todo lo referente a los orígenes históricos de esta misma experiencia ha tenido menor presencia» (Altuna, 2008, p. 87). Y sorprende por la importancia del "hecho cooperativo» como elemento central en el desarrollo económico, social y político de algunos territorios y, en general, del conjunto del país. Además sacaremos a la luz periodos del cooperativismo vasco olvidados o minorizados. Todo ello con el fin de responder a la pregunta de investigación con la necesaria perspectiva histórica, lo que coadyuvará a la tarea común de definir la función social de las cooperativas, tema cuya producción académica es a todas luces insuficiente.

La segunda parte, el análisis práctico, tratará más profundamente el entorno cooperativo vasco. Para ello se ha planteado un trabajo de campo con diferentes entrevistas. Estas entrevistas se realizan mediante una estrategia de intervención en dos paneles: personas socias trabajadoras y personas investigadoras de temas cooperativos. Para establecer ambas categorías, serán considerados investigadores aquellas personas que de una u otra manera han desarrollado un trabajo intelectual público - por ejemplo, publicaciones en revistas académicas, conferencias o charlas - respecto a alguna materia cooperativa. Sin querer restar valor al pensamiento de las personas trabajadoras, o incluso al desarrollo de una filosofía del trabajo en un sentido gramsciano ${ }^{3}$, de quienes valoramos su aportación como relevante en tanto experiencia viva del cooperativismo.

Para el tratamiento de las mismas nos adscribimos a una disciplina llamada Análisis Crítico del Discurso (ACD) y en concreto a la línea defen-

2 Huyendo así de una historiografía clásica, puesto que la historia es disruptiva y en ella los ciclos o épocas se entremezclan y ligan de una manera compleja de diferenciar, siguiendo las propuestas de historiadores como Antonio Manuel Hespanha.

3 Es decir, construyendo un sistema de pensamiento propio de estos trabajadores, Gramsci delimitó esta filosofía popular en un espacio y sociedad determinadas y lo denomino «sentido común». 
dida por la lingüista Luisa Martín Rojo. Para esta disciplina, tanto la práctica textual como la discursiva y la social (sus análisis, lo que generan en un espacio, etc.) del discurso son dimensiones indisociables del mismo (Martín Rojo, 2014, p. 157). El ACD, como ella misma señala, plantea dos objetivos: a) el análisis del discurso y como éstos estructuran la sociedad (2014, p. 166) y, b) el de "explorar el poder generador del discurso» (2014, p. 160). La idea que subyace con nuestra metodología es observar si la idea sobre la función social cooperativa es la misma para sus «observadores» que para sus «integrantes». E introducimos este tipo de análisis crítico puesto que la gran parte de la literatura en torno al cooperativismo vasco reproduce cierto esquema mítico, sobre todo respecto a Mondragon, en la que "this critical point of view is absent from most of the academic literature made from management's perspective» (Heras-Saizarbitoria, 2014, p. 3), cosa que también criticó Kasmir (1999, p. 25).

\section{Contexto histórico}

$\mathrm{Al}$ establecer los antecedentes históricos —o genealogías - de las cooperativas se suele recurrir a las tradiciones primigenias vascas (el modelo familiar y de comunidad, la propiedad comunal y privada, etc.) pero destaca por encima de todas una que se ve como principio originador del cooperativismo: el auzolan ${ }^{4}$. De hecho, la referencia al auzolan parece ser una cita casi obligada cuando se habla de cooperativas vascas, tal y como puede comprobarse en (Altuna, 2008, p. 90) (Lertxundi, 2002, p. 51) o en (Itçaina, 2010, p. 74).

Sin querer entrar en debates más complejos, parece una evidencia que el «hecho cooperativo» en Euskal Herria es en sí, un elemento diferenciador. El desarrollo del mismo puede obedecer a ciertas diferencias sociales o culturales respecto a otras comunidades. Como bien se cita en Auñamendi, el auzolan «es una forma antiquísima de trabajo en común que tiene su equivalente en multitud de sociedades europeas medievales y modernas» (Estornés y Garmendia, 2020, n/c). Algunos de esos equivalentes son la Huebra o Hermandad en Castilla o la Hacendera en León sin que ello haya traído parejo un cooperativismo similar, por lo que el auzolan no puede actuar de síntesis completa de este movimiento. Creemos que todas estas referencias a las tradiciones primigenias, o como se ha llegado a decir los «tiempos inmemoriales» (Altuna, 2008, p. 89), responden a un dis-

4 Auzolana es la «Prestación vecinal gratuita en beneficio público» (Estornés y Garmendia, $2020, \mathrm{n} / \mathrm{c}$ ). En esta, los convecinos aportan trabajo no remunerado a la conservación y mantenimiento de caminos, acequias y otras infraestructuras comunales, además de situaciones de urgencia como incendios. 
curso legitimador de la mitificación de las cooperativas vascas, en el más puro sentido de Cassirer ${ }^{5}$. También, en un sentido weberiano, la literatura académica ha venido a vincular el movimiento cooperativista con un relato mítico de los trabajos comunales creando un discurso inmemorial en torno al mismo que legitime las propias cooperativas en sí, creando este esquema mítico, idea por la cual parece que Sharryn Kasmir tituló su obra como «El Mito de Mondragón». Por otro lado, también se ha dicho que "Los antecedentes de la autogestión socialista vasca se encuentran en el Fuero de Avellaneda (siglo XVI)» (Lertxundi, 2002, p. 33) pero tampoco puede ser una explicación per se el hecho de que estas tradiciones políticas, aunque de base más igualitaria que las de otros modelos coetáneos, sean el elemento diferenciador del movimiento cooperativo vasco. Analizar todas estas diferencias desde cierta distancia metodológica podría ayudar a ofrecer visiones históricas revisadas más fidedignas. Los límites de un trabajo como este no nos permitieron profundizar, pero creemos conveniente reseñar este planteamiento.

Hemos de hacer aquí otro inciso sobre los «olvidos históricos», en este caso en torno al papel de la mujer en la historia del cooperativismo, del que siempre ha formado parte aunque haya sido invisibilizada. Desde los pioneros de Rochdale, de los que Ana Tweedale fue parte, hasta las Cooperativas de mujeres en la Experiencia Cooperativa de Mondragon, la mujer no ha sido referenciada suficientemente en el saber académico.

Por otro lado, y con carácter previo, hemos de delimitar nuestro objeto de estudio. Así, evitando entrar a analizar otro tipo de sociedades, asociaciones, mutualidades o cofradías que debido a sus prácticas y dinámicas se asemejen a las cooperativas utilizaremos una acepción de cooperativa más restringida puesto que entenderemos como tales aquellas sociedades con dicha forma jurídica —o con dicha denominación, a pesar de no ser jurídicamente una sociedad cooperativa- Y Y si bien la doctrina es unánime en situar el nacimiento de las cooperativas en la Rochdale Equitable Pioneers Society, en (Bengoetxea, 2016, p. 207) o en (Monzón, 2003), creada en 1844 en la ciudad de Rochdale (Inglaterra), en el caso vasco parece que los primeros experimentos cooperativos se dieron algunas décadas después, en torno a los años 1870 , mediante diferentes agrupaciones obreras mutuales de consumo, socorros mutuos y de crédito (Lezamiz, s.f., p. 43). Así ya podemos hablar de la primera etapa del cooperativismo vasco.

5 Para (Cassirer, 1985) frente al mundo caótico, las sociedades responden a sus sentimientos más primitivos y preguntas trascendentales mediante la creación de simbólicos comunes que canalicen éstos y otorguen un sentido al mundo donde viven, este simbólico común se traduce en los llamados «mitos». Su explicación se centra en el Estado, pero ello no obsta a que se pueda dar en otras sociedades o comunidades. 


\subsection{El Cooperativismo de Anteguerra}

En el año 1884 y 1886 se crean las primeras cooperativas de consumo en Barakaldo - la Sociedad Cooperativa de Obreros de Barakaldo- y Araya - la Unión Obrera de Araya - respectivamente. En 1887 se crean también con forma cooperativa la Sociedad de Consumo de los Obreros de Sestao. Tanto la experiencia de Barakaldo como la de Sestao están «al amparo de los Altos Hornos y sus socios fueron trabajadores de la empresa» (Roussell y Albóniga, 1994, p. 6). Será en 1892 cuando, ligada a una cooperativa de consumo, nazca la primera cooperativa industrial vasca: La Eibarresa, a la que seguirán Dano Bat y Omega. Pero será a raíz de una huelga cuando nacerá la que fuese la cooperativa industrial con mayor importancia del periodo: Alfa, que transformó su producción de armas por la de las conocidas máquinas de coser con el mismo nombre. Estas cooperativas forman allá donde se fundan pequeños mundos cooperativos en torno a la fábrica, al crear viviendas cooperativas — las llamadas «casas baratas»y economatos sociales, también cooperativos.

Paralelamente en Navarra, a principios del siglo xx, ocurrirá un fenómeno similar en torno a las Cajas de Ahorros, siendo Anastasio Mutuberría el fundador de la primera cooperativa de crédito en Tafalla, a la que seguirían las de Olite y otros pueblos. Estas cooperativas surgían del movimiento raiffeisianista $^{6}$; entidades surgidas de la filantropía vinculadas a la Iglesia y al sector agrícola. Así, en 1912, gracias a la tarea de algunos sacerdotes se habían creado en Navarra «155 cajas rurales navarras» (Yoldi, 1916, p. 526), «número superior a cualquier otra región española.» (Salvador, 1988, p. 425).

Además en Gipuzkoa, Araba y el rural vizcaíno se dieron, en esta época, cooperativas vinculadas a la Iglesia católica que nacían de las cajas de ahorro, aunque de menor potencia que las navarras. Eran sociedades mutuales, en el sentido estricto de la palabra, puesto que no llegaron a desarrollar lógicas cooperativas como lo haría el cooperativismo industrial de Bilbao y la margen izquierda, vid. (Arrieta et al., 1998).

Salvando la notable experiencia navarra, que tenía cierto contenido social en torno a la doctrina del Rerum Novarum de León XIII, las cooperativas solían estar directamente vinculadas a partidos o sindicatos obreros. Así, Alfa, nació auspiciada por la UGT y el PSOE, incluso con una importante aportación económica (Lertxundi, 2002, pp. 59 y 67) y «uno de los requisitos de ingreso como socio consistía en participar de alguna agrupación socialista» (Altuna, 2008, p. 93). Esto hacía que su actuación estuviese

${ }^{6}$ Llamadas así por Friedrich Wilhelm Raiffeisen, el promotor de este tipo de este cooperativismo agrario tan particular nacido en Alemania. 
condicionada por dos tipos de objetivos: por un lado, proveer a los obreros de la zona de un empleo digno y estable y por otro conseguir de las cooperativas los fondos necesarios para continuar con la acción política y sindical. Al respecto, "el semanario bilbaíno "La Lucha de Clases», órgano del PSOE y de la UGT en el País Vasco» decía que las cooperativas «se fundan para ser las vacas lecheras del Partido» es decir «las que mantienen y dan vida a los periódicos, las que construyen Casas del Pueblo y Círculos Socialistas.» (Olábarri, 1985, p. 301) en (Lertxundi, 2002, p. 67).

Y pese a la importancia de las iniciativas cooperativas «ugetistas», el sindicalismo nacionalista vasco, agrupado en ELA, también promovió estas cooperativas. Se proponía crear cooperativas de consumo en los pueblos donde hubiese agrupaciones de trabajadores vascos y su obra se centró más en estas que en las de producción. «La primera cooperativa patrocinada por ELA/STV («Vasca de Consumos de Bilbao») data de 1919, a la que siguieron rápidamente otras en Durango, Algorta, Baracaldo y San Salvador del Valle» y a diferencia de las de corte socialista «Estas cooperativas estaban abiertas también a socios no solidarios y funcionaban según los principios rochdalianos» (Azurmendi, 1992, p. 603). A este cooperativismo vasco se le ha catalogado "como tardío, dinámico, versátil y poliédrico» (Altuna, 2008 , p. 91). Lo que quizás habría que añadir es que, a causa de la dictadura franquista, no ha vuelto a haber un cooperativismo obrero como aquel. Su función social no solo comprendía la generación de empleo sino proveer con los excedentes a las organizaciones obreras de la época. Aunque ello no obsta que la experiencia navarra tuviese un carácter más filantrópico y social que no político. A este "cooperativismo de anteguerra», como lo llama Azurmendi, le sucede la Experiencia Cooperativa de Mondragon. Y pese a que Arizmendiarrieta, inspirador y fundador de la misma, conocía estas experiencias, su visión del cooperativismo le hizo rehusar las experiencias con «idearios políticos en pugna» y en cambio buscó "un modelo de cooperativa único y solidario, que se limite a recoger los intereses obreros efectivos, ideológicamente neutral, en el que la clase trabajadora pueda volver a encontrar su unidad» (Azurmendi, 1992, p. 605).

\subsection{Cooperativismo "de necesidad», Iglesia y Comunitarismo}

Ya en los años 50, las iniciativas mutualísticas se suelen agrupar a la luz de la Experiencia de Mondragon. Este grupo cooperativo ocupará gran parte de nuestra exposición ya que es ciertamente la experiencia más representativa de las cooperativas vascas en el mundo, y también en la propia Euskal Herria, a veces con una visión muy «mondragon-céntrica» de la historia de su cooperativismo. El propio Grupo reconoce que el nacimiento 
del mismo «busca atender las necesidades de una sociedad de postguerra. Una sociedad dividida, traumatizada, con necesidades básicas no cubiertas, ideologizada política y religiosamente, en un contexto de mercado autárquico» (Ortega y Uriarte, 2015, p. 4). De los mismos autores tomamos el calificativo de cooperativismo «de la necesidad».

Esta experiencia cooperativa y muchas otras fuera del Grupo nacen del impulso de parte de la Iglesia Católica, que seguía los principios de la Doctrina Social de la Iglesia. «Lo demuestra que la mayoría estén bajo la advocación y dedicación de algún santo», sirvan de ejemplo «la Cooperativa San José de Abandio, Cooperativa San José de Mondragón o Cooperativa Sagrado Corazón de Jesús de Elorrio, etc.» (Lertxundi, 2002, p. 59). En el caso de Mondragon existe una figura central en el diseño, desarrollo y en la propia definición política del grupo y es el Padre José Arizmendiarrieta. Para comprender más el pensamiento de Arizmendiarrieta tenemos que analizar su visión comunitarista como crítica al capitalismo liberal y al socialismo real, una particular «tercera vía» aplicada a la realidad comarcal de Deba Goiena.

\subsubsection{Pensamiento de José María Arizmendiarrieta}

Sintetizar el pensamiento de Arizmendiarrieta es una tarea compleja, o como diría Azurmendi «inabarcable». Por ello trataremos de seleccionar la parte de su obra más relevante respecto a nuestro trabajo. Remitimos para un mayor desarrollo a la tesis de Joxe Azurmendi: El Hombre Cooperativo, obra clave para el análisis de su pensamiento. Aún y todo, hay quién ha planteado si esta obra simplemente recogió su pensamiento o generó una determinada visión del mismo. En todo caso, sí que podemos decir que marcado por el periodo que le tocó vivir y enfrentándose a una sociedad devastada, Arizmendiarrieta planteó una crítica constante al socialismo soviético y al liberalismo capitalista, por ello trató de enlazar conceptos que él consideró claves en torno a una filosofía práctica: Trabajo, Persona, Comunidad y Cooperativa son los más importantes. Azurmendi sitúa sus fuentes en cuatro ejes: la Doctrina Social de la Iglesia, Maritain y Mounier, la tradición social vasca — en la que destacan los «sacerdotes propagandistas" por un lado y el "socialismo eibarrés» por otro- y los clásicos del cooperativismo (1992, p. 37). Se han dado diferentes definiciones de su pensamiento tratando de clasificarlo ${ }^{7}$ pero lo único que podemos tener claro

7 Así, se le ha definido como «a mitad de camino entre el colectivismo marxista y el individualismo liberal, su ideario es próximo al socialismo democrático, aunque pasado por el tamiz de la Doctrina Social de la Iglesia» (Altuna, 2008, p. 37) o incluso "Arizmendiarrieta se aproxima más al humanismo socialista originario de Proudhon, Owen y otros, que al pensamiento marxista» (Altuna, 2008, p. 44). 
es que su pensamiento es una filosofía propia y sui generis, que continuaría desarrollando y adaptando durante toda su vida.

Frente a la crisis civilizatoria que él creía que sufrían las sociedades de la época plantea un modelo de empresa donde la persona sea el centro, pero no en un sentido liberal individualista sino dentro de la comunidad. Esto se consigue al tener en cuenta «que la dignidad humana se vive y se desarrolla en la comunidad, que no se alcanza la madurez mientras la persona no participe en esa comunidad». Así, esa dignidad tenía dos pilares, el trabajo y la educación. Este trabajo digno se convierte en el elemento central de la cooperativa y del propio país, hasta el punto de que Azurmendi dirá que «nadie, como Arizmendiarrieta, le ha puesto de manifiesto - al pueblo vasco- que, en última instancia, la historia de un pueblo descansa sobre el fundamento, aparentemente humilde, de su trabajo» (1992, p. 40). El segundo elemento es la instrucción técnica y ética de los hombres y mujeres - y recalcamos mujeres porque así lo haría él también-y complementa a este trabajo digno. Ahora bien, "Arizmendiarrieta siempre subrayó la importancia de la variable económica: la experiencia cooperativa debía constatar su viabilidad» ya que «estaba en juego demostrar la mayoría de edad de la clase trabajadora, así como su madurez para el autogobierno y la autoorganización» (Altuna, 2008, p. 72).

El sacerdote otorga a esta relación persona-comunidad una forma específica de trabajo: la cooperativa. Además, en un preciso marco político de comunidad, puesto que «el concepto de Arizmendiarrieta no se agota en la fábrica: también son comunidad el pueblo, la nación y, en definitiva, toda la humanidad» (Altuna, 2008, pp. 43-44). Para él, «no existe una formula universal de empresa cooperativa (...) la Experiencia de Mondragon «es la que, correspondiendo al espíritu tradicional vasco, ha sido posible en un momento determinado» (Azurmendi 2000, n/c) en (Altuna 2008, p. 47).

\subsubsection{La mujer en Mondragon}

Entre los «olvidos históricos» mencionados, el papel de la mujer en la historia del cooperativismo parece ser uno de los más flagrantes. Es en este cooperativismo «de la necesidad» donde encontramos uno de los casos donde se ejemplifica esta participación olvidada. Así, era habitual que las mujeres con trabajos remunerados en las cooperativas de Mondragon, y en general de todas las mujeres de la época, abandonasen este cuando se casaban, siendo relegadas al trabajo invisible y no remunerado. Muchas cooperativas incluían el matrimonio como pérdida de la condición de socia, por ejemplo en el art. 44 del Reglamento de Régimen Interior del Grupo ULARCO. Las protestas de las socias de ULARCO llevaron a crear una comisión de estudio del tema, de la que Arizmendiarrieta formó parte. La comisión llegó a unas conclusiones 
en las que apostaban por eliminar todo tipo de trabas al trabajo de la mujer casada en las cooperativas de Mondragon. Esta situación no era exclusiva de ULARCO, sino que se repetía en otras cooperativas.

Por ello, un grupo de 17 mujeres decidió empoderarse y constituyó Auzo Lagun. Así, "En 1968 fuimos la primera cooperativa fundada e integrada por mujeres» (Auzo Lagun, 2015, n/c) [Énfasis original] ${ }^{8}$. La idea subyacente era que ellas pudiesen tener un papel propio en el entorno del trabajo remunerado, sin subyugarse al marido una vez casadas. De ahí que las primeras conquistas sociales de Auzo Lagun fuesen la creación de la primera guardería privada del Estado español y la supresión de las cláusulas que restringían su incorporación al trabajo ${ }^{9}$. El propio Arizmendiarrieta escribió al respecto y definió a Auzo Lagun como «un expediente y un medio de promoción de BIENESTAR (...) para hacer más sensible la contribución de la MUJER a la misma» (Arizmendiarrieta, 1970, p. 1). De hecho, «Su postura se podría resumir en la frase «dejad que la mujer decida por sí misma su suerte (...) «la mitad de las personas adultas no tienen por qué regir los destinos de la otra mitad» (Ib. 142)» (Azurmendi, 1992, p. 323).

Analizando hoy esa perspectiva es interesante retener la reproducción interna de la división sexual del trabajo, ya que pese a que las mujeres solteras y posteriormente casadas conformaban la plantilla de numerosas fábricas, Auzo Lagun se dedicó a la preparación y distribución de comida ${ }^{10}$. En todo caso, y esto sirva de mero ejemplo, las cooperativas cuentan también con numerosos casos de lucha de empoderamiento y feminista. La Huelga de ULGOR de 1974 fue protagonizada por mujeres, que fueron las despedidas, y estas han tenido un papel primordial en la organización de las cooperativas. Ahora alejándonos relativamente de Mondragon entraremos a analizar un fenómeno de este periodo que surgió en cierta manera de las mismas necesidades colectivas.

8 Auzo Lagun solo contrató a mujeres hasta 1977, cuando se incorporó el primer hombre, al no lograr encontrar una mujer para el puesto, y con ello se eliminó la discriminación positiva de los estatutos.

9 Nótese que la polémica de ULARCO, y el fin de la autorización marital y la posibilidad de suscribir seguros propios, se da un ańo después de la constitución de Auzo Lagun.

${ }^{10}$ El discurso de Mondragon al respecto, en su revista propia, refleja estas conquistas así, «Las cooperativistas cambiaron su mentalidad e interiorizaron definitivamente que formaban parte del mundo laboral» (TU Lankide, 2019, n/c). Sin embargo, no parece descabellado pensar que fue precisamente su conciencia sobre que no formaban parte del mundo laboral remunerado lo que las llevó a crear Auzo Lagun, por lo que no sabemos hasta que punto el pensamiento de las propias mujeres quedó, de nuevo, relegado. 


\subsubsection{ECONOMATOS Y COOPERATIVAS DE CONSUMO}

En paralelo a los inicios del cooperativismo mondragonés, y sin ser ajeno al mismo - el nacimiento de la cooperativa de consumo EROSKI puede explicarse desde ambas perspectivas - hemos de mencionar los economatos sociales y cooperativas de consumo de empresa. Muchos de estos economatos se crearon por obligación legal puesto que el Decreto de 21 de marzo de 1958 obligaba a crear Economatos laborales para las empresas de más de 500 empleados y otros muchos habían surgido a imagen y semejanza de las primeras cooperativas de consumo ligadas al movimiento obrero, vid. supra. Vinculadas a la industria nacían como una remuneración a sus empleados en formas de descuentos, para adquirir productos básicos (azúcar, huevos, leche, aceite, etc.) a un precio menor al de mercado.

Durante la década de los 60, estas cooperativas tuvieron un importante desarrollo puesto que llegaron a alcanzar, sobre todo en Bizkaia, importantes cifras de facturación. Su estructura se hizo mediante Uniones Territoriales de Cooperativas - UTECO por sus siglas - que tuvieron presencia en los cuatro territorios de Hegoalde ${ }^{11}$. Estas UTECO eran capaces de gestionar la obligación impuesta a las empresas de manera externa y así, centralizándose, se reducían costes. La de Bizkaia llegó a contar con una panificadora propia y cooperativizó una producción de aceite en Sevilla que luego distribuía entre sus cooperativas (Roussell y Albóniga, 1994, p. 22). En todo caso, existieron otros ejemplos fuera de Bizkaia como la Cooperativa de consumo de Michelín en Lasarte-Oria (Gipuzkoa), o la Cooperativa Zapardiel (Araba).

Las transformaciones socioeconómicas del mercado español en materia de distribución de alimentos hicieron que estos economatos y cooperativas de consumo no pudiesen competir con las grandes superficies. Tan solo es destacable por su peso y pervivencia, EROSKI, que nació en el marco de estas cooperativas de consumo pero fue capaz de consolidarse como el cuarto distribuidor alimentario estatal, en gran parte auspiciado por el Grupo Mondragon. Para un mayor desarrollo, hemos de remitir a (Roussell y Albóniga, 1994). La siguiente fase histórica no responde a estas «dinámicas de necesidad» de la clase obrera vasca, sino a procesos donde las sociedades han superado estos estadios precarios, se consolidan y optan por la búsqueda del bienestar.

11 De los pocos datos estadísticos que existen, podemos afirmar que en 1974 se cuen$\tan 74$ cooperativas de consumo y 98. 963 socios en la Comunidad Autónoma del País Vasco, mientras que en Navarra el fenómeno fue menor. Su registro, que incluye las de Aragón, no llega a las 35 cooperativas (Saéz, 1978, pp. 40 y 43). 


\subsection{Cooperativismo del Bienestar}

Una vez superadas las necesidades más básicas de la posguerra, las cooperativas empiezan a sufrir cambios en su estructura debido a su importante crecimiento. Además, en la década de los 70 , se sucederán una serie de eventos que condicionaran notablemente el devenir de Euskal Herria: las crisis económicas del petróleo, los cambios políticos en Hegoalde y la conflictividad social son algunos de ellos. Pero, además, todo esto coincidirá con procesos determinantes dentro de las cooperativas del valle del Leintz como la muerte de Arizmendiarrieta o la Huelga de Ulgor de 1974. Ello, hace que aquí se inicie un ciclo diferenciado en el cooperativismo de Mondragon, que hemos llamado Cooperativismo del Bienestar que, aunque se puede tratar desde diferentes visiones, se explicará desde la perspectiva política y socioeconómica.

\subsubsection{POLÍ́TICA, IDENTIDAD Y “COMUNIDAD MORAL VASCA» ${ }^{12}$}

El nuevo ciclo de la filosofía política que inaugura Mayo del 68 (el debate cultural, una nueva ola de feminismo o el incipiente anticolonialismo) provoca cambios en todos los espectros ideológicos de Europa. En Hegoalde la coincidencia de estos cambios con el fin de la dictadura hace resurgir el debate político a la esfera pública, cosa que tuvo una repercusión inmediata en las cooperativas. Se reflejará todo este proceso mediante el análisis de un caso que nos ofrece suficientes matices para entenderlo en su complejidad. Se trata de la Huelga de Ulgor de 1974.

En pleno crecimiento de ULGOR, primera cooperativa de «la Experiencia de Mondragon", se convocó una huelga con motivo de las condiciones salariales, sin embargo esta tenía claras razones política de trasfondo. El Consejo Rector consideró que era una huelga política y como estas estaban prohibidas en las cooperativas despidió a algunas trabajadoras, que precisamente se habían significado ideológicamente. Este acontecimiento, por otro lado, excepcional y casi único en la historia del Grupo, nos permite ver como la discusión ideológica estaba en el centro mismo del debate. Desde el Grupo se ha dicho que «la huelga de 1974 no tuvo relevancia en sí misma» sino por los debates "que tendrán lugar antes y después de la huelga y que estarán contenidas en esta» (Altuna, 2008, p. 139) pero hay quien, como

12 Marianne Heiberg describe con este término la comunidad que se creó en algunas zonas de Hegoalde (Heiberg, 1980), y más concretamente en comarcas de la CAPV, en la que «los nacionalistas vascos crearon un universo paralelo al del régimen. Los elementos de este universo eran las Ikastolas, las fiestas, el renacer cultural y las cooperativas de Mondragón» (Heiberg, 1989, p. 225) en (Kasmir, 1999, p. 127). 
Kasmir, sitúa la Huelga de ULGOR como el punto álgido de la pugna de los nacionalismos vascos por la hegemonía del movimiento cooperativo. Y es que "ya que las cooperativas de Mondragon se habían fijado en el nacionalismo vasco como inspiración para su política y como fuente de cohesión ideológica (...) el cooperativismo era el modelo de producción nacionalista vasco" (Heiberg, 1989, p. 225) en (Kasmir, 1999, p. 127). Ahora bien, la misma Kasmir matiza ¿Qué nacionalismo vasco? La respuesta viene dada en torno a la postura adoptada tanto por el mundo jeltzale ${ }^{13}$ como desde el movimiento abertzale ${ }^{14}$. Los primeros siempre habían defendido las cooperativas de Mondragon, de hecho, destacados miembros de las diputaciones y del Gobierno de Vitoria provenían orgánicamente de las cooperativas —el mismo Lehendakari Ardanza-. Respecto a los segundos, la cuestión es más compleja. Además, en todo esto hay que sumar la figura de Arizmendiarrieta que sostenía un debate ideológico con ambos nacionalismos mediante publicaciones y artículos.

La ezkerra abertzale había venido sosteniendo una posición favorable a las cooperativas vascas del modelo mondragonés. Sin embargo empezaran a surgir algunas críticas en torno a ciertas prácticas de las cooperativas hacia los socios trabajadores «de abajo». Sin embargo, esas críticas no se harán públicas hasta 1965. La primera fue contra Arizmendiarrieta debido al otorgamiento de la Medalla de Oro al Mérito en el Trabajo por las autoridades franquistas $^{15}$. Estas críticas se acentuarán más a partir de 1971, fecha de la VI ${ }^{a}$ Asamblea en la que ETA, quedará fracturara "en miríadas de pequeños grupos» (Azurmendi, 1992, p. 624) con ideologías contrapuestas. Así mientras que las criticas de ETA $V^{a}$ eran puntuales, otras facciones llegaron a decir que «el cooperativismo es rechazado en su totalidad como MÉTODO y como SIS-

13 Jeltzale es una palabra en euskera cuyo significado más común es el de miembro o simpatizante del PNV. Aun así, Elhuyar Hiztegia también lo traduce como «seguidor de Sabino Arana Goiri»

14 Para el Elhuyar abertzale se traduce como "patriota» o «nacionalista». Pese a ello su uso se suele asociar a los miembros y seguidores de la Izquierda nacionalista vasca, llamada también abertzale. Aunque válida, la utilización de la palabra para designar a los nacionalistas en general o a los miembros del PNV es menor.

15 Zutik, órgano de comunicación del movimiento, se expresó con unas duras palabras en una nota, que aunque no llegó a ser publicada resulta de interés. Decía

«Franco ya sabe a quién premia y a quién castiga. A decir verdad, pocas veces se equivoca. Visto así es como se comprende la medalla que ha recibido J.M. Arizmendiarrieta, dirigente de las cooperativas. Lo merecía... de parte de Franco.

Cuando hay una huelga, los trabajadores no quieren salir, ¿Qué postura es esa? ¿Tendremos que oír a estas alturas que el cooperativismo es la solución a los trabajadores vascos y la muerte del capitalismo?»

(ETA 1981, p. 4) en (Kasmir 1999, p. 86). 
TEMA» (Azurmendi, 1992, p. 626), pensando evidentemente en Mondragon. Por el contrario el inspirador de la Experiencia era muy consciente de estas críticas y defendió su modelo en contra del llamado «inflacionismo revolucionario» (Azurmendi, 1992, p. 628).

Este contexto político tan candente en Hegoalde e internacionalmente, provoca una agitación máxima en la comarcada durante la Huelga de ULGOR. Por ejemplo, LCR-ETA VI repartió una hoja clandestina con unas historietas con el título de "Historia del Cooperativismo e Historia de un brujo que desarrolló unas fuerzas y no pudo controlarlas» que criticaba duramente la historia del movimiento cooperativo y volvían al tema de la Medalla al Trabajo. Sorprendentemente, el cura no hizo un llamamiento a la disciplina sino que cargó contra la dirección, instándoles a que mantuviesen el espíritu cooperativo para evitar tendencias burocráticas o funcionariales que desvinculasen a los socios de la constante renovación cooperativa.

En su estudio sobre la experiencia de Mondragon, LANKI, destaca la introducción de importantes cambios a raíz de ese debate: la limitación a 500 socios cuando fuera posible, regulación de las huelgas por razones externas, reformas en el Consejo Social o formaciones sobre los mecanismos internos de resolución de conflictos (Altuna, 2008, p. 156). Pero lo que sí que cabe destacar es que la pugna por la hegemonía política del nacionalismo vasco y por el control del movimiento cooperativo no quedó resuelta con dichas medidas, siguió candente. No es casual que durante los años siguientes en Iparralde, centro político del movimiento abertzale durante la dictadura, se desarrollase un cooperativismo tan político como veremos más adelante.

\subsubsection{Desarrollo empresarial: de las Agrupaciones Comarcales a la Corporación}

Se puede hablar del desarrollo socioeconómico de las cooperativas de Mondragon mediante una ingente producción académica que, sobre datos económicos, nos ofrecen numerosos indicadores de su buena marcha. No podemos desatender estos datos, pero quizás lo que mejor refleja este desarrollo económico y su implicación para el grupo fue el paso de los grupos comarcales a la Mondragon Corporación Cooperativa.

El sostenido crecimiento de la economía española durante los años 70 y 80, salvando las crisis del petróleo, se consolidó sobre altas tasas de paro y una reconversión industrial durísima para la CAPV. Aun así, la economía vasca fue creciendo de manera notable ${ }^{16}$. Además se produjo un do-

16 El crecimiento interanual de la CAPV se situó entre el 10\% y el 14\%, excepto el ańo de la crisis, 1983, que fue del 9\% (Euskal Estatistika Erakundea/Instituto Vasco de Estadística, 2008 (act. 2017), n/c) 
ble proceso migratorio, el debido al éxodo rural interno y el de un notable crecimiento poblacional en ciertas zonas de la CAPV proveniente de determinadas regiones del Estado Español ${ }^{17}$. Mondragon tuvo un gran éxito al conseguir captar los excedentes del ahorro en torno a la caja cooperativa, Caja Laboral, y en torno al sistema de protección social propio, Lagun Aro. Todo ello, facilitó que durante los años de caída de ventas en el sector industrial pudiesen recolocar a socios trabajadores en el propio entramado cooperativo. Siendo en la crisis de los 90 donde Mondragon demuestra su excepcional resistencia económica logrando obtener una posición de mercado única. Esta posición hará que la entrada en el mercado europeo y la salida de la crisis provoquen en Mondragon la entrada a una época de notables beneficios económicos. El empleo en Mondragon pasó de 19.669 personas en 1986 a 60.200 en 2001, y de hecho, en 2006 se llegaría hasta los 103.731 (Altuna, 2008, p. 162). Gran parte de este crecimiento vino dado por la internacionalización del grupo, un episodio especialmente polémico para el mundo cooperativo.

Ahora bien, este discurso sobre las virtudes del crecimiento, tan extendido en la academia, suele ocultar otras realidades. Para hacer frente a todos estos retos, la organización en grupos comarcales de Mondragon tuvo que cambiar y la exigencia en el lugar de trabajo se hizo especialmente dura. Puede sintetizarse de la siguiente manera;

a) La estructura del grupo pasó de configurarse en torno a Grupos comarcales, que vinculaban cooperativas por razón territorial, a Divisiones sectoriales, que aglutinaba por sector de actividad (industria, distribución y financiero). Esto se planteó como solución a «series de producción pequeñas, costes altos y productividad bajas que se traducían en una baja competitividad» (Altuna, 2008, p. 164), pero hizo que se perdiese cierto «arraigo local».

b) La organización laboral sufrió cambios importantes no solo porque las escalas salariales aumentaron de 1:3 a 1:6, sino porque se intentó hacer más eficiente el trabajo de cada persona, incluso mediante mecanismos que analizaban los movimientos realizados de cada uno y se dio un aumento notable de la contratación temporal. Además, el Grupo se fija el objetivo de internacionalizar las partes productivas con un trabajo manual intensivo a países con menores costes de mano de obra, y esto se materializa con la apertura de la

17 «Entre 1950 y 1980, emigraron al País Vasco 524.402 españoles residentes en otras provincias, equivalentes al $24,1 \%$ de la población vasca residente en 1980 . Entre 1980 y 2000, emigraron del País Vasco 157.417 residentes, equivalentes al 7,2\%» de la población vasca de 1980 (Alcaide, 2007, p. 173). 
primera filial en China en el 1995-hoy MCC tiene más de 60 filiales (Altuna, 2008, pp. 167-173).

c) Todos estos cambios se dieron en el Congreso Cooperativo de 1991, en el que además, esta restructuración culminó con el cambio de denominación de Grupo Cooperativo Mondragon (proveniente del Congreso de 1987), a la de Mondragon Corporación Cooperativa, o $\mathrm{MCC}^{18}$.

d) Fruto de las iniciativas de educación que desde el inicio existían dentro del Grupo, en 1997 nace Mondragon Unibertsitatea, una universidad cooperativa singular configurada como entidad sin ánimo de lucro. A la vez, fruto de la promoción del euskera desde las cooperativas del Grupo se ayuda a consolidar algunas ikastolas ${ }^{19}$.

Algunas conclusiones son ya evidentes. La primera, destaca una constante búsqueda de eficiencia y competitividad en el mercado europeo y global. Una anécdota clarificadora de ello es que en 2011, Auzo Lagun, la cooperativa de mujeres, cambió su nombre por Ausolan para facilitar la pronunciación en otros idiomas ${ }^{20}$. Mondragon aprovechó los cambios necesarios para afrontar la coyuntura económica de una forma admirable resistiendo las crisis económicas con intercooperación y protección social propia y reinvirtiendo los excedentes en la comunidad. Sin embargo, parece que por el camino relegó a los trabajadores a ser meros espectadores. En nuestra opinión, esto colisiona con los principios mutuales que fundan las cooperativas, mucho más si ahondamos en el debate de la extracción de plusvalía mediante filiales de la periferia capitalista. En resumen, determinados acontecimientos habidos en las cooperativas nacidas en Arrasate,

18 La explicación al cambio de denominación las podemos encontrar en las Normas del Congreso, actualizado a 18 de enero de 2008, que cita (Altuna, 2008, p. 164): «La denominación sintetiza tres rasgos emblemáticos del movimiento cooperativo de Mondragón:

- Mondragón: «identifica el origen singular de la experiencia y aporta el reconocimiento internacional como paradigma del movimiento cooperativo".

- Corporación: «identifica una entidad diversificada en sus componentes operando bajo una Unidad de Dirección y permita, adicionalmente, la utilización del concepto grupo para proyectar imágenes parciales de la Corporación hacia mercados objetivos específicos».

- Cooperativa: «incorpora un valor irrenunciable de identidad sociocultural diferenciador del modelo».

19 Estas cooperativas de educación ya desarrollaban su labor desde antes del franquismo y han tenido un papel clave en la normalización y fomento de la lengua vasca en Euskal Herria.

${ }^{20}$ Literalmente se explica que "con el ánimo de facilitar la pronunciación, se creó la marca Ausolan, que posibilita mantener la fonética (dado que en euskera la ' $z$ ' se pronuncia con un sonido similar a la 's') facilitando la correcta pronunciación» (TU Lankide, 2019, n/c) 
y especialmente el Congreso de 1991, parecen ser un punto de inflexión. MCC triunfó en lo económico y lo revirtió en su comunidad pero la lógica era de corporación internacional y no de pequeñas cooperativas arraigadas a la comunidad.

El apelativo que califica como «del Bienestar» este apartado lo hemos tomado de un texto de LANKI, que también explica que en esta fase en la que «Las necesidades básicas están cubiertas, las ideologías van decayendo, el contexto de mercado es de competencia creciente (entrada en la Unión Económica Europea), surge un pragmatismo en la acción que busca el bienestar, el "nivel de vida" y donde "se prioriza lo cuantitativo a lo cualitativo" (Ortega y Uriarte, 2015, p. 3). La cita es indicativa de la percepción de MCC sobre su propio desarrollo puesto que citan factores externos como piezas claves que comprometieron la acción de sus cooperativas sin considerar también los posibles elementos internos. Estos factores surgen de una descarnada búsqueda de la competitividad en un mercado mundial predatorio con el objetivo de sostener la estructura creada en la matriz. El coste pudo suponer la ruptura con los modelos cooperativos más tempranos pero MCC entendió que eran transformaciones necesarias para la sostenibilidad económica y acordes con sus principios. Este análisis tiende a dejar fuera del esquema la importancia del debate teórico que se producía en las sociedades europeas, trasladados aquí en forma de hegemonía entre los nacionalismos vascos y entre sus facciones. Entre la muerte de J.M. Arizmendiarrieta en 1976 y el Congreso Cooperativo de 1991 cambiaron mucho las cosas dentro de las estructuras del Grupo. Aunque el discurso de MCC no suele mencionarlo, cabe preguntarse si en vida del fundador se hubiesen adoptado estas medidas que se alejaban de su pensamiento comunitarista. Vista esta transformación en el cooperativismo vasco, quizás la más importante de su historia, hay que decir que la sociedad vasca también sufrió cambios de la misma relevancia.

Dentro de esta etapa, por su coincidencia temporal, incluimos un epígrafe sobre un cooperativismo que siguió con el espíritu originario de las cooperativas pero con unas prácticas diferentes. Como ya hemos dicho se dio en Iparralde, donde el movimiento abertzale continuó siendo activo y potente en el territorio.

\subsubsection{La versión de Iparralde: el CoOperativismo identitario}

El notable éxito de Mondragon hará surgir voces que vean posible trasladar ese modelo a Iparralde. "La difusión de los postulados del co- 
lonialismo interno en paralelo al surgimiento del nacionalismo encuentra en el modelo cooperativo un instrumento político de respuesta y acción para parte del movimiento nacionalista vasco» según Itçaina (2005) en (Ahedo, 2006, p. 447), lo que provoca el nacimiento de un cooperativismo propio en la región del Estado francés. Así, en 1975, nace Copelec, primera cooperativa constituida con dicha forma jurídica (Société coopérative ouvrière de production o SCOP, por sus siglas en francés). Le seguirán otras muchas como Alki, Denek, Berria o Telecoop, la mayoría ligadas al sector de la agricultura. En una región en la que los jóvenes parecen no tener alternativas laborales en el campo, y ante el éxodo rural, estas cooperativas tratan de ofrecer una respuesta política. Todo este estallido cristalizará en la creación de dos entidades claves: Hemen, asociación sin ánimo de lucro para el apoyo económico de las cooperativas que fue creada en 1979, y cuyos objetivos se encuadran, según sus palabras, como parte del espíritu de Mondragon «miniaturizado» (Hemen Elkartea, 2017, n/c); y Herrikoa, nacida en 1981 como sociedad de capital-riesgo de apoyo a la creación y desarrollo de empresas solidarias. Las bases de este movimiento cooperativo se articulan con una marcada identidad en torno a "un même sentiment identitaire, une même communauté d'intérêt, dépassant le seul profit immédiat pour investir dans l'emploi à moyen et long terme " (Hemen Elkartea, 2017, n/c). Por ello, no es casual que la primigenia agrupación de cooperativas se denominase Lana, trabajo en euskera. Lana «se pone en marcha en 1982 en torno a los militantes de las SCOP Alki y Denek». Sus «funciones de promoción, intervención, asistencia e integración [de cooperativas] permiten que Lana se defina de una forma militante: Lana es más que una unidad técnica, es un movimiento.» (Itçaina, 2005) en (Ahedo, 2006, p. 449).

El propio Itçaina recalca también ese «sentimiento identitario» (Itçaina, 2005) que parece tan claro en el proyecto de Ipar Euskal Herria. Y es con esta idea con la que bautizamos esta etapa como "cooperativismo identitario». Pese al desarrollo inicial y sus logros en la comarca, este movimiento se fue difuminando en otros movimientos sociales, lingüísticos y políticos, de tal manera que hoy, no puede hablarse de un cooperativismo diferenciado en Iparralde. Lo que sí es reseñable es la influencia de esta fase en el movimiento cooperativista vasco, o al menos en alguna de sus expresiones. Destaca entre estas expresiones el Eusko o Euskal Moneta, una iniciativa más propia de la Economía social — la ley francesa reconoce las monedas sociales como parte de esta-. La propuesta de Iparralde suponía una diferencia con todo lo anterior, cosa que anunciaba la llegada de cambios en el movimiento cooperativo, por lo que quizás se pueda clasificar como una etapa de transición. Sin embargo, antes habría que determinar si cabe hablar o no de un nuevo ciclo cooperativo, huelga decir que son numero- 
sas las voces que lo afirman, pero menos las que reconocen en Iparralde sus antecedentes.

\section{4. ¿El nuevo ciclo cooperativo?}

Ya en los años 90, Kasmir parecía prever cambios en la estructura cooperativa. Ella, al explicar la huelga general de 1994, convocada contra la reforma laboral de Felipe González, hace especial hincapié en que a diferencia de otras huelgas generales los cooperativistas habían acudido al paro laboral, en lo que parecía un cambio de tendencia. La antropóloga vaticinaba que esto "podría anunciar que se está llegando a una nueva fase en las cooperativas, en la que la organización interna puede conducir al activismo y a la solidaridad con el resto del movimiento obrero» y los trabajadores generen dinámicas democráticas y de participación en las cooperativas y con los sindicatos que «que lleguen a construir un nuevo modelo en Mondragon.» (Kasmir, 1999, p. 118).

El propio Mondragon habla de un cambio de ciclo, cuyos inicios sitúa en torno a los ańos 2000, y cuyo punto de no retorno fue la caída de Fagor. Se refieren a ello cuando explican que el legado de Fagor son una serie de aprendizajes que dan las claves para «un cooperativismo más autoexigente (...) imprescindible para encarar los desafíos económicos, sociales y humanos que enfrentan nuestras cooperativas y sociedades en este nuevo ciclo histórico» (Ortega y Uriarte, 2015, p. 4). Para MCC este nuevo ciclo histórico ha de ser el del cooperativismo de la «autoexigencia y de la co-responsabilidad» (Ortega y Uriarte, 2015, p. 5). A sensu contrario, el título puede sugerir que el cooperativismo anterior no ha sido ni exigente consigo mismo ni co-responsable. Aunque preferimos pensar que el nombre pretende aludir a otro tipo de responsabilidades, parece existir en MCC la idea de que los fallos en Fagor se deben a la dejadez de algunos socios y su constante queja contra la dirección. Kasmir, al respecto, dice que "the bankruptcy of Fagor Electrodomésticos exposes the limits of Mondragon to overcome contradictions of the capitallabor relationship" y por ello "the larger task of social transformation requires strategies and alliances that lead co-op members and activists to take a role in a wider movement for social betterment, at local and global scales" (2016, p. 57).

El cambio es evidente, si en los 90, el nuevo ciclo apuntaba al «activismo y solidaridad con el movimiento obrero" y mencionaba a los sindicatos, ahora habla de «estrategias y alianzas con miembros y activistas de movimientos por el bienestar social a escala local y global». De hecho, sería lógico pensar que este nuevo ciclo puede vincularse con la creación de 
nuevos movimientos cooperativistas en búsqueda de modelos alternativos, críticos o simplemente diferentes a los de Mondragon. Las reflexiones de Kasmir se asemejan a la propuesta del cooperativismo comprometido o ekintzaile $^{21}$, y en concreto a la de Olatukoop, cuyo nombre parece apuntar a esta idea de nuevo ciclo que parece flotar en el aire. Como Ekaitz, uno de sus miembros, nos comentó "Olatukoop también es la consecuencia de una nueva ola cooperativa. O sea, Olatukoop no crea esa ola, Olatukoop... surge en esa ola...y la potencia seguramente».

Olatukoop es un proyecto que nace en 2014 como asociación de cooperativas. Se basa en los principios de la ACI y los del software libre como nexos de unión que se reconocen mutuamente en una situación de igual a igual en torno a unas Bases Abiertas - Oinarri Irekiak-. Cuenta con unas cincuenta entidades, la mayoría cooperativas, distribuidas por Gipuzkoa y alguna en Iparralde. Sus dinámicas de participación distan mucho de la estructura de grupo cooperativo y su posicionamiento político 22 tiene bastante semejanza con el cooperativismo identitario de Iparralde. Además, a diferencia de MCC, Olatukoop sí que trabaja con los sindicatos, al menos con LAB y ELA.

Las referencias a la nueva fase que se hacen desde Mondragon y el nacimiento de un cooperativismo organizado alternativamente a la corporación apuntan a un nuevo ciclo del cooperativismo, hablar de esto es aún aventurado hoy. La propia quiebra de Fagor, a la par que una oportunidad, ha actuado como revulsivo a ciertas dinámicas internas de cambio, y por otro lado, Olatukoop es poco conocido fuera de ciertos círculos académicos o políticos por lo que habrá que atender a su desarrollo.

En esta propuesta de una historiografía del cooperativismo vasco moderno hemos repasado desde las primeras cooperativas vinculadas al movimiento obrero hasta Olatukoop. Pasando por Iparralde y la que es, sin nin-

${ }^{21}$ Ekintzaile, de traducción compleja, tiene una doble acepción — según Elhuyar Hiztegia - tanto de activista como de emprendedor. Aquí nos referiremos con ambas acepciones a Olatukoop. Ellos mismos se autodenominan indistintamente Ekonomia sozial berria eta ekintzailetasun como Ekonomia sozial eta eraldatzailearen, y en castellano Economía Social y Transformadora.

${ }^{22}$ Lógica de recursos comunes, Autogestión de los integrantes, Promover la solidaridad personal y comunitaria y Sostenibilidad y bien común. Esto se articula en torno a cuatro Líneas de acción o de trabajo — Lan-ildoak - que incluyen la Memoria cooperativa de Euskal Herria, Programas de emprendizaje cooperativo — Ekintzailetza sozial eta kooperatiboa -, Intercooperación y mutualismo y, por último, el de lograr una Economía que esté al servicio de la vida — bizigarritasuna-. 
guna duda, la mayor contribución del cooperativismo vasco al mundo: el Grupo Mondragon. La idea general del análisis histórico es la importancia respecto a la generación de empleo de las cooperativas en Euskal Herria. Sin embargo, las particularidades de cada fase son notables puesto que en no pocas ocasiones existen otras tareas sociales, desde fortalecer movimientos políticos hasta razones éticas o filantrópicas. De hecho, estas tensiones y particularidades se expresan dentro de cada ciclo pero también entre cada fase. Sin olvidar que quedan temas necesarios por tratar para completar este análisis, incluimos una tabla resumen que puede ayudar a sintetizar el capítulo.
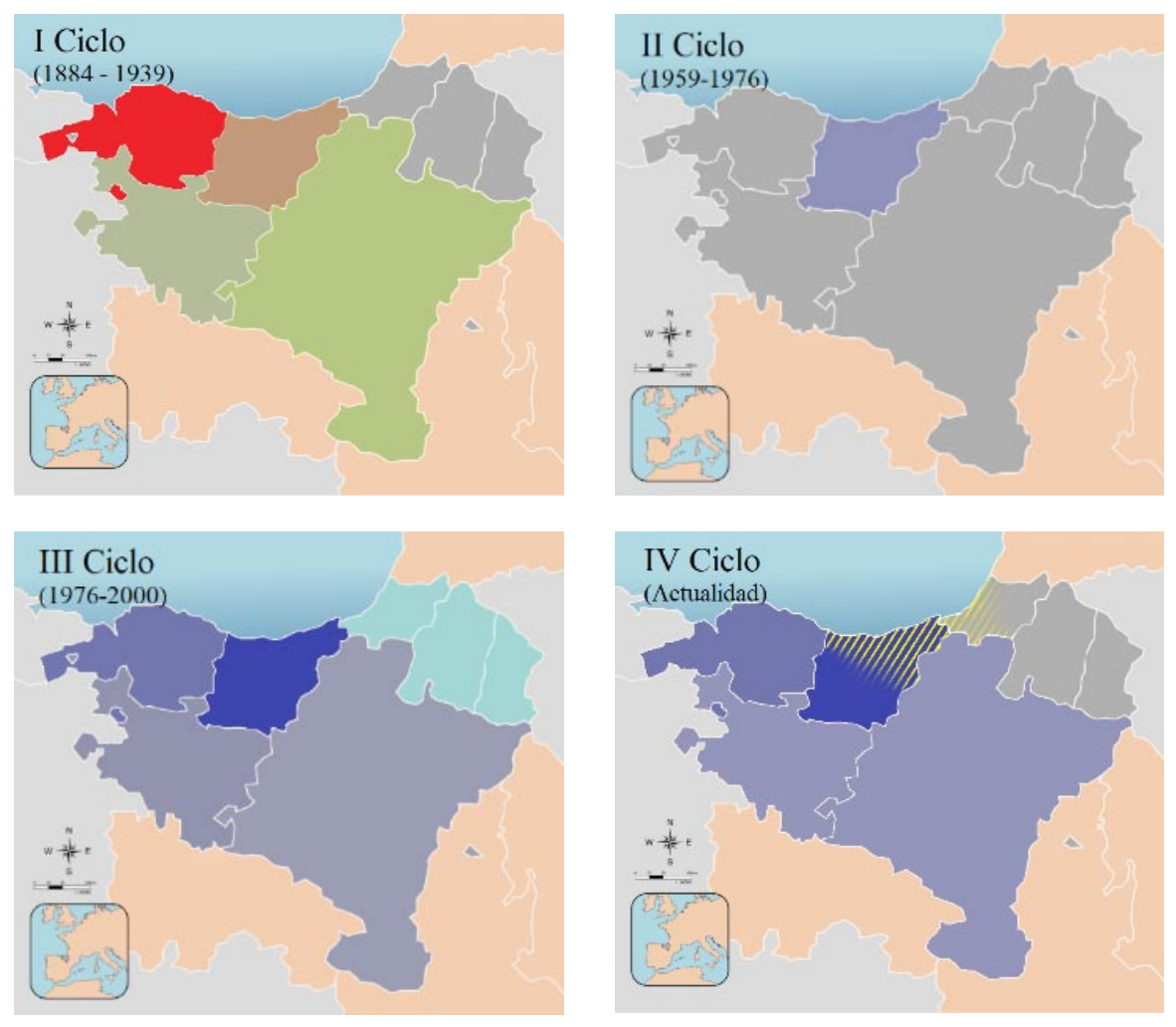

Fuente. Elaboración propia.

\section{Tabla 1}




\section{Trabajo de campo}

El trabajo de campo basado en un panel de entrevistados ${ }^{23}$ que comprende a cuatro socios trabajadores de cooperativas vascas - tanto de Mondragon como de Olatukoop-y dos investigadores en la materia cooperativa — uno de ellos de la Administración de la CAPV y otro socio cooperativista-, arroja interesantes conclusiones que complementan lo expuesto en el contexto histórico. También se incluye en este apartado el análisis de las últimas producciones académicas. Siguiendo el Análisis Crítico del Discurso, en este apartado no solo se analizarán las entrevistas sino también el contexto discursivo generado en ellas. Por ello, hay que matizar que todas las entrevistas han sido realizadas en diferentes ciudades del Territorio Histórico de Gipuzkoa: Deba, Donostia, Errenteria, Irun, Ordizia y Tolosa; y generalmente en espacios públicos como bares o restaurantes, aunque algunas de ellas — precisamente las de los expertos - tuvieron lugar en bibliotecas y centros institucionales, fuera todas del lugar de trabajo, la Iron Cage de Weber ${ }^{24}$.

\subsection{Trabajo digno y comunidad: ¿Humanity at work?}

La primera de nuestras conclusiones es que el cooperativismo vasco tiene como principal función la de garantizar el empleo digno y de calidad en la comunidad. Esta función social tan repetida por sus integrantes parece el legado directo de Arizmendiarrieta. Los socios más veteranos y los más recientes reconocen esta aportación de una u otra manera. Incluso el socio de Olatukoop explica que en «muchas zonas de Euskal Herria, es el motor económico (...) Un factor de igualdad bastante importante, aunque le hagamos su críticas». También Luis, investigador y miembro de la Administración autonómica, refleja esta idea al hablar de la existencia de dos fondos propios irrepartibles «uno para el mantenimiento de la propia empresa (FRO) y por tanto para el mantenimiento del empleo, que es la función social, otro destinado a la educación, que se aplica a la colectividad (cultura, fomento del euskera, formación profesional...) (COFIP)».

Este planteamiento ha sido una constante en la historiografía del cooperativismo vasco, incluso en el cooperativismo de anteguerra, aunque ex-

23 Para preservar su confidencialidad, y aunque no se nos ha solicitado expresamente, asignaremos seudónimos a cada una de estas personas.

${ }^{24}$ Siguiendo aquí una idea ya utilizada en un estudio de Heras-Saizarbitoria sobre cooperativismo en el que «the interviews were carried out outside Weber's symbolic Iron Cage (...), that is. outside the workplace, away from the metaphorical instrument of dominant authority" (2014, p. 6). 
presado de otra manera. Esto tiene su más claro ejemplo en el cooperativismo de Iparralde, nacido con un "espíritu de Mondragon miniaturizado» (Hemen Elkartea, 2017) (vid. supra 2.3.3). Así Ahedo para explicar la función social de las cooperativas de Iparralde, cita a Itçaina que explica que «el objetivo principal de las cooperativas que se crean desde los 70 es claro: garantizar el empleo y el trabajo en el país. Una función que contrasta con la dimensión social de inserción de los desempleados que asumen la mayor parte de las experiencias francesas» (Ahedo, 2006, p. 448).

Partiendo de esta simple, y a la vez compleja, respuesta podemos ir ańadiendo diferentes matices. El primero de ellos es el que se refiere a la perspectiva económica de esa función social, y se refiere a la viabilidad económica. Existe una preocupación al respecto que puede explicarse con las palabras de Ińaki, socio e investigador de la MU,

En el pensamiento de Arizmendiarrieta, teniendo una visión muy comunitaria, la eficiencia empresarial era fundamental, digamos que era la base para el posterior desarrollo comunitario. (...) En Mondragon las cooperativas tienen que ser rentables en su contexto de mercado... es decir, sin eso, nos olvidamos del resto.

Esto es, la función social queda supeditada a la viabilidad económica. Los socios trabajadores expresan una idea similar aunque lo hacen en unos términos diferentes - tal que "si la empresa va bien a ti te va a ir bien y si la empresa va mal a ti te va a ir mal» o "yo creo que está bien, si ganas, ganas y si pierdes, pierdes» o incluso «la intercooperación es una herramienta, para mí... cojonuda. La intercooperación es organizados en función de, antes era por geografía luego fue por sectores y tal..., es al que le va mal recibe y al que le va bien aporta»- Y Y han sido precisamente esos sólidos mecanismos de intercooperación los que han permitido a la corporación cooperativa articular un notable éxito socioempresarial. Sin embargo, y pese al funcionamiento casi sin sobresaltos de estos mecanismos durante 60 años, en 2013 ni la ayuda del Grupo pudo salvar a Fagor Electrodomésticos, FED, primera cooperativa del Grupo Mondragon, del concurso de acreedores. Algo que los cooperativistas tienen, todavía hoy, muy presente. En las entrevistas la preocupación por la vialidad económica de los proyectos cooperativos ha derivado siempre en Fagor. Esto no es algo nuevo, como también reconoce el discurso «oficial» de Mondragon: «La crisis de Fagor Electrodomésticos azuza, por tanto, el debate sobre la función social y la vocación transformadora del cooperativismo de Mondragón» (Ortega y Uriarte, 2015, p. 10). El tema ha devenido un topoi en las entrevistas, no solo por la caída simbólica de ese "buque insignia», tan repetido por varios sino porque precisamente el hundimiento de este buque provocó la pér- 
dida de innumerables puestos de trabajo de socios cooperativistas, contraviniendo la función social propia de la cooperativa. Además de las obvias implicaciones que ha tenido el concurso de acreedores de FED en MCC y en las propias personas socias de las cooperativas.

Hay que decir, que durante el período de realización de las entrevistas la UPV/EHU publicó parte de un ensayo más completo sobre la caída de FED, (Basterretxea et al., 2019). El artículo explicaba las causas sociolaborales que provocaron la quiebra en torno a la política de sociatura - que los autores llamaron «nepotismo»-, a las bajas laborales y a otros factores. La prensa vasca y foránea se hizo un amplio eco del mismo, a veces acusados de cierto sensacionalismo. Este artículo suscitó una viva polémica en el seno de la comunidad cooperativa - grupos de WhatsApp, charlas en el trabajo o debates en los bares- como nos comentaron los propios socios. El revuelo causado llegó hasta el punto de que Ordaindu —una de las asociaciones de socios de Fagor que no pudo recuperar su aportación- hizo un comunicado al hilo del estudio. Este, tras criticar duramente a la MU, a MCC y a la antigua dirección de FED concluía diciendo que «culpar a los socios de a pie siempre es un recurso fácil pero... no cuela» (Ordaindu elkartea, 2019, n/c).

Ese «socios de a pie» nos remite a la tensión de «los de abajo y los de arriba» de la que ya habló Kasmir en los años 90. Uno de nuestros entrevistados fue Mikel, exdirectivo de Fagor durante el concurso de acreedores. Este reconocía que había miembros de la cooperativa que se veían tensionados por esta relación «Para ellos (Ordaindu) hay dos cooperativas, están los de arriba que son lo que manejan la pasta y los que hacen con la pasta lo que quieren y están los de abajo» aunque él consideraba que esa diferencia no se manifestaba como una tensión, a diferencia de Kasmir y Ordaindu, él dijo: «Los de la corbata y los de la grasa, toda la vida, existe, pero existe en Mondragón y existe en las sociedades anónimas». Además hay parte de la doctrina que da la razón a Mikel, "In the case of the MCE, this decoupling would not appear to give rise to any internal tension between worker-memberowners and managers of the type that might be envisaged in a community-based organization» (Heras-Saizarbitoria 2014, p. 12). Solo Ińaki, el investigador de la MU, reconocía una tensión «en la gobernanza cooperativa, esa tensión interna entre Vosotros [Consejo de Dirección] y Nosotros [Consejo Social], eso no aporta» y lo vinculó a una cierta malinterpretación del rol del Consejo Social «como un sindicalismo que se opone».

Los socios trabajadores se expresaban en estos términos pero no lo reconocían como un elemento de polarización. Javi, un reciente socio de Mondragon, lo expresó llanamente diciendo que «Yo no les llamo jefes, les llamo responsables, cada uno tiene su labor. No es más dueño que yo o no es más que yo». Y estos socios, a pesar de ser considerados «de abajo» 
ni se veían tensionados por esta diferencia ni compartían los posicionamientos de Ordaindu. Al hablar del tema, expresaron sus dudas en torno a las aportaciones sociales que los cooperativistas no pudieron cobrar por la declaración del concurso puesto que es «una bolsa que no es tuya, (...) Lo que pasa que claro, cuando lo ves ahí, dices «no, eso ya es mío» no, no es tuyo... o sea, es tuyo si es... y si no, no es». Para ellos la relación de los socios cooperativistas respecto a los fondos propios no había sido la adecuada. Quizás para explicar esto hay que matizar que el concurso de acreedores se declara cuando las cooperativas deciden no hacer una segunda aportación a FED, puesto que la primera, de 70 millones de euros, había durado apenas seis meses. Tendremos que esperar a la completa publicación del artículo, o a que Mondragon complemente la obra de (Ortega y Uriarte, 2015) para poder obtener unas conclusiones más sólidas en torno al discurso de la caída de Fagor. Será clave atender a qué y cómo se producen estas puesto que afectarán a esa simbiosis entre la función social y la viabilidad económica.

Fuera de esta relación entre la viabilidad económica y la generación de empleo y de la existencia o no de una tensión interna entre «los de arriba y los de abajo», en las entrevistas han aparecido otros temas reseñables. Javi, al ser preguntado por la función social contestó "¿iMi visión o lo que nos venden como cooperativa?» con esto, parecía querer señalar que en esa función social se aprecian ciertos matices o críticas que no han sido recogidos o trabajados por el discurso hegemónico del cooperativismo. Muchas de estas críticas derivan de los cambios en la estructura productiva de MCC en la década de los 90, (vid. supra apartado 2.3.2). Se han identificado dos matices: el primero, el de los cambios en los sistemas de selección y de sociatura y el segundo, sobre las condiciones de parte de la plantilla no socia. Aunque podría haber un tercero respecto al surgimiento de las filiales lo reservamos al apartado 3.3, puesto que ha sido la academia la que ha avivado dicho debate. Estos matices ponen en tela de juicio la función social expresada por la estructura de MCC, que, parafraseando su lema, podríamos expresar así ¿ Humanity at work?

Así, los cambios productivos en MCC trajeron asociados una serie de preguntas sin una respuesta inequívoca como ¿Qué implican las diferentes categorías de socios y trabajadores? ¿Y entre las diferentes posiciones de las escalas salariales? Respecto al estatus jurídico de socio-no socio, los primeros no parecen observar una división clara o marcada entre ambas, más allá de los privilegios de los socios frente a los meros empleados que quieren serlo, puesto "que quién no es socio puede tragar» y por ello «va a alzar la voz menos que quién es socio" (Javi). Esto respecto a los trabajadores no socios del mismo rango productivo. $\mathrm{Y}$ es que existen en las cooperativas, al menos en algunas, un tipo de trabajador que Javi definió como matxacas 
- los obreros temporales que realizan duros trabajos eventuales-. La contratación de estos trabajadores, normalmente migrantes, se hace durante cortos periodos de tiempo, inferiores a los tres años, «¿Por qué? Porque si le hago socio me va a empezar a pedir condiciones dignas y no me interesa. Y eso un poco hipocresía también es» (Javi).

A pesar de ser socio, la actitud de Javi hacia las condiciones de estos trabajadores no ha variado, esto es, prima "su visión" a aquella "que nos venden». Si Javi expresa esa "hipocresía» de las cooperativas es porque entiende que la existencia de matxacas es algo extraño al hecho cooperativo. Que personas socias hagan este tipo de críticas implica dos cosas. La primera, y más importante, es que mantienen ciertos vínculos de identificación con el resto de personas trabajadoras de las cooperativas, socias o no, y la segunda, que su poder de influencia en la política laboral de cooperativas del grupo queda en cuestión. Esa solidaridad interna entre trabajadores ofrece cierta esperanza puesto que afianzar estos vínculos puede ser la manera de tejer nuevas alianzas que retomen el proyecto humanista de las cooperativas.

Por otro lado, la trascendencia de esos cambios productivos en la política de sociatura y contratación es extensible a todos los trabajadores de las cooperativas. Los socios más antiguos expresan estas paradojas, así

Eso ha cambiado... ha cambiado la sociedad y ha cambiado la cooperativa. Ya la gente... antes igual entrabas en la cooperativa $y$, casi casi, era... tu empresa. (...) A día de hoy la gente entra a trabajar y parece que es un asalariado. Es como... yo entro a trabajar en una máquina y yo soy el empleado de esta máquina que me manda. (José Miguel)

«Parecer un asalariado» es la condena tácita de los socios a las nuevas dinámicas del cooperativismo industrial. La crítica es doble; tanto a la autonomía del puesto de trabajo donde ahora se sienten «empleados de una máquina» pero también contra las direcciones de las cooperativas porque han dejado de sentir que es «su empresa». Mikel, el exdirectivo de Fagor, centró su crítica en otro aspecto: las malas condiciones en que han quedado los socios trabajadores de Fagor en las reubicaciones - personas cuyos gastos en transporte superan al nuevo sueldo, cooperativistas a los que tras dos años reubicados no se les hace socios, etc.-. Analizar esta perspectiva es interesante, y hasta donde conocemos no se está realizando. No solo eso, existe en el discurso "hegemónico» la idea de que las reubicaciones de los socios de FED ha sido un esfuerzo titánico - y sin duda lo ha sidopero también que este proceso se ha culminado con éxito, cosa que Mikel pone en duda. Centra su crítica en cuestionar la dignidad de ese trabajo y en concreto, en la mala gestión de la política laboral con los antiguos socios 
de Fagor. Por tanto, reformular las cooperativas en torno a un nuevo ciclo pasará también por plantear el trabajo - otrora central en la construcción de Mondragon - como algo «digno" tanto para trabajadores como para socios.

Solo queda por añadir, las críticas que el miembro de Olatukoop reseñó de esa función social. Pese a que inicialmente Ekaitz critica cierta preferencia comarcal en MCC, su mayor crítica al cooperativismo mondragonés es respecto a lo que él llama despolitización, «Mondragon renuncia al cooperativismo como... como política. $\mathrm{O}$ sea habla del cooperativismo, como movimiento cooperativo, pero luego renuncia a ser herramienta política más allá de ser lobby ¿¿no?». Aquí, Ekaitz señala un aspecto que también apuntó Kasmir, «la idea de que las cooperativas representan un pragmatismo libre de ideologías, tanto dentro del País Vasco como en los países que han adaptado el sistema es un aspecto importante del mito de Mondragón» (1999, p. 35). Pero ¿Qué relación guarda esa "preferencia comarcal» y la «despolitización» con la función social? En primer lugar, Ekaitz se refiere a la segunda parte de la función social, la del arraigo al territorio del empleo cooperativo. Para él no asumir Euskal Herria en su total extensión y no promover el cooperativismo en los siete territorios es algo «lamentable» para un cooperativismo como el de MCC. En nuestra opinión, quizás sea necesario huir de un marco «mondragon-céntrico» y meramente industrial para hablar del cooperativismo. Las ikastolas, que en el territorio son ejemplo paradigmático del cooperativismo en el sector educativo, tienen una implantación que se da - aunque de manera desigual — en toda Euskal Herria. Por ello, repensar la función social del cooperativismo en su conjunto es una materia pendiente. Respecto a la crítica de la «despolitización» se enmarca en una dialéctica entre Olatukoop y el Grupo Mondragon sustanciosa de cara a pensar el nuevo ciclo histórico.

\subsubsection{El NUEVO Ciclo COOperativo Y SU FUnCión SOCIAL}

En las entrevistas de los investigadores y en la de Ekaitz de Olatukoop han surgido temas comunes que difieren de los de las personas trabajadoras. Los primeros mencionan la relación entre Mondragon, Olatukoop y REAS y debaten sobre el papel de los sindicatos en el cooperativismo vasco, asuntos ambos ajenos a los trabajadores entrevistados, que además no conocen ni han oído hablar de Olatukoop, para ellos, el cooperativismo empieza y es el proyecto del Grupo Mondragon.

El primero de estos temas se circunscribe en el debate sobre el papel de cada una de las entidades mencionadas. Mientras que Mondragon lidera el cooperativismo, y protagoniza el discurso de todo el espectro de la Economía social, la Red de Redes de Economía Alternativa y Solidaria (REAS) ha ve- 
nido siendo el referente principal de la Economía Solidaria en Hegoalde. El socio investigador de MU, Ińaki reconocía la referencialidad de REAS pero añadía que «desde su origen ha sido una comunidad articulada en torno a Bilbo, y bastante alejada desde mi punto de vista a la comunidad euskaldun, parecía como que la Economía Solidaria era parte de otra comunidad».

El nacimiento de Olatukoop ańade un tercero en discordia que no se ubica en ninguno de los dos, «nosotros no somos una tercera vía, pero no... no estamos ni en Mondragon ni en REAS. Políticamente igual estamos más cerca de los que tienen visión política en REAS, pero de estructura y de cómo tendría que ser un cooperativismo fuerte, con Mondragon» (Ekaitz). Podemos decir ya que el debate entre la Economía Social y la Economía Solidaria ha tenido una repercusión directa en Euskal Herria, donde se ha reproducido con un eje adicional: el de la comunidad euskaldun. El paradigma desde el que situarse configura así uno de los puntos en que difieren las agrupaciones a la hora de entender este nuevo ciclo histórico.

El segundo de estos debates es respecto a la participación de los sindicatos. Pese a que Arizmendiarrieta «estimaba de la máxima importancia, por tanto, alcanzar una estrecha colaboración entre el cooperativismo y el sindicalismo" (Azurmendi 2000, n/c) en (Altuna, 2008, p. 72) en Mondragon el sindicalismo brilla por su ausencia, de hecho en las entrevistas con sus socios apenas se han mencionado. En cambio, en Olatukoop se colabora con ellos, al menos con LAB y ELA. Esta falta de relación es multicausal, pero influye mucho la pasividad, que el investigador de la Administración, Luis, achaca a los sindicatos. Ekaitz es más claro y reconoce que costará «años... costará décadas, pero yo creo que el nuevo cooperativismo transformador o solidario tiene una relación más cercana a los sindicatos y la estrategia tiene que ser compartida». Es esta la segunda de las distancias entre ambos modelos cooperativos que se reivindican como nuevo ciclo.

Con todo, existen también puntos en común reconocibles entre ambos cooperativismos. Entre ellos, el de buscar cambios productivos que integren la perspectiva social, ecológica y feminista - que en Olatukoop sintetizan mediante el concepto la sostenibilidad de la vida, en euskera, bizigarritasuna. Ambos parecen tener claro qué representa la función social para cada uno de ellos. Así Ińaki nos dijo,

En Mondragon, transformador es que tú seas capaz, cómo comunidad, de generar, por ejemplo, una economía basada en unos valores pero, que aspiren a incidir en la centralidad de la economia y de la sociedad (...) Aunque la vocación transformadora en Mondragon haya ido evolucionando desde su origen, y podamos intuir que ahora se encuentre ante un tercer ciclo histórico, su aspiración es esa, la de generar condiciones de vida para la mayoria de una comarca, de una sociedad. Ahi reside su valor. 
Mientras que en Olatukoop su visión es que, «El lugar social del cooperativismo, (es) verse también como agente principal de emancipación. Eso es lo que debería de ser. (...) llegar a todos los ámbitos de la economía: pero para las necesidades de las personas, no desde una óptica productivista» (Ekaitz).

Hasta aquí hemos podido comprobar como el empleo de calidad y arraigado al territorio ha sido el leitmotiv de las cooperativas vascas nacidas a la luz de la Experiencia de Mondragon, e incluso de otros momentos de la historiografía cooperativa. Sin embargo, la función social puede ser criticada desde varias perspectivas. Tanto desde su relación necesaria con la variable económica como aquellas que inciden en la calidad del trabajo cooperativo, de los socios y de los no socios (fijos, eventuales o matxacas). Aunque pueda parecer irrelevante, en un sentido arizmendiano la construcción de la dignidad humana no puede permitir que el desarrollo como persona dentro de la comunidad simbólica —el pueblo o la cooperativa- queden relegados a la suscripción del estatus jurídico de socio cooperativista. Si el impulsor del Grupo Mondragon decía que la persona madura en la comunidad, y los trabajadores demuestran su madurez mediante la viabilidad económica de la cooperativa, nosotros podemos decir que las cooperativas maduran cuando todos sus miembros viven en condiciones dignas acordes a su condición de personas. Existen esperanzas en torno a la redefinición de la comunidad cooperativa en lo que se ha llamado «nuevo ciclo histórico». En este, la construcción de un Mondragon post-Fagor y el papel de Olatukoop son fundamentales. Entre ellos difieren en grandes temas como los sindicatos o el paradigma académico en el que se sitúan, per comparten preocupaciones en torno al feminismo, el ecologismo o la recomarcalización que pueden apuntar a un nuevo periodo en la historia del cooperativismo vasco. Entramos a analizar ahora la relación entre la Cooperativa y esa Comunidad simbólica que se crea desde la Persona.

\subsection{La Identidad Cooperativa y la Vasquitud}

Si la generación de empleo de calidad parece ser la función social de las cooperativas, también hemos visto que los matices y críticas expuestos delimitan la comunidad a la que esta se dirige: las personas socias cooperativistas. El porqué de esta diferenciación socios-no socios puede deberse a la imposibilidad de generar una identidad cooperativa más allá del socio 
cooperativista. Esta identidad es una parte inseparable de la función social, y aunque sus socios no la reconozcan, sí la expresan de una u otra forma. La idea sobre la identidad cooperativa surgió cuando Mikel planteó una serie de preguntas en torno a los razones de crear una cooperativa y no otra sociedad jurídica. Respecto a esta fungibilidad o intercambiabilidad societaria, Mikel decía,

Tu montas una cooperativa de cuatro y una SL de cuatro, tienes lo mismo, cada uno tiene el 25\% de lo mismo pero, si es verdad, que la cooperativa desde el punto de vista de resultado va a aportar menos que la SL. ¿Si? Pero al negocio en sí, al negocio en sí, una forma jurídica no le va a aportar más que la otra. Ni al negocio, ni a la evolución, ni a la implicación y tal. Eso es así, eso creo yo, la forma jurídica, en sí, no aporta más.

Quizás Mikel pueda tener razón, puesto que la doctrina no es unánime a qué aportan las cooperativas al modelo de negocio. Sin embargo, lo que hemos comprobado es que, pese a la afirmación de Mikel, sí puede decirse que las cooperativas han creado un sentimiento de pertenencia mutuo y colectivo que trasciende el ámbito de la propia empresa, e incluso del propio Grupo Mondragon. Así, los cooperativistas en general hablan de su pertenencia «a las cooperativas», o al "mundo cooperativo» para referirse a su recorrido laboral en la empresa cooperativa. Hasta tal punto que, José Ángel nos habló de esta pertenencia con cierto orgullo, nos dijo «No cambiaría por nada, a día de hoy, el haber trabajado en una cooperativa, no lo cambiaría pero ni por el forro». De la misma manera, tras explicar a Ekaitz la metodología y preguntarle sobre su clasificación como experto o como socio trabajador, él contestó "como Cooperativista».

Este sentir de pertenencia a una comunidad mayor a la de la propia empresa es un hecho característico y diferencial de las cooperativas, cosa impensable en las sociedades de capital por la mera forma jurídica. Esta vinculación identitaria es el nexo entre Persona y Comunidad que teorizó Arizmendiarrieta. Pero no solo es la forma jurídica, otro de los anclajes de esta identidad es, sin duda, el territorio. Como explicó Luis, esa identidad va inseparablemente ligada al pueblo o comarca de dónde vienen las cooperativas,

Orona está en Hernani, Ampo está en Ordizia. Ampo en lugar de poner la pasta en Coca Cola o en no sé qué pone la pasta en el equipo de Rugby de Ordizia. Porque ellos son de Ordizia. Orona igual, ellos generan un parque empresarial y ni se les pasaria por la cabeza hacerlo en un sitio que no fuese Hernani. 
Él parecía poner en valor esta triple vinculación socio-cooperativa-territorio como algo diferencial y único del cooperativismo vasco respecto al de otras sociedades del entorno.

¿Sabes cómo se llama la mayor cooperativa de consumo italiana? Se llama Coop., Coop. Italia... ¿Sabes cómo se llama la mayor cooperativa inglesa? Cooperative. ¿Sabes cómo se llama la mayor cooperativa de consumo en España y en Euskadi? Eroski. [Y en referencia al Grupo Mondragon dijo] En Italia ponen encima la palabra cooperativa, aqui ponen encima el PUEBLO.

A nuestro modo de ver, existe entre los socios una vinculación con la cooperativa, y de estas con el territorio. A esto ayuda el hecho de que las cooperativas de Mondragon naciesen fuertemente organizadas en torno a los grupos comarcales. Además en el proceso de transformación a las agrupaciones sectoriales hubo cooperativas que se resistieron a la unión por tipo de actividad - como ULMA - y otras que decidieron mantener la intercooperación comarcal junto con la sectorial —como el propio Grupo Fagor, antes ULGOR, que además fue el primer grupo comarcal, como nos relató Ińaki-. Los socios reconocen esta vinculación cuando dicen que las cooperativas destinan los fondos obligatorios «a los pueblos de nuestros alrededores, a temas sociales, del euskera..., eh, a ikastolas (...) por ejemplo, se quiere montar un frontón en el pueblo, colaboran con eso... Sí, normalmente se da un poquito a tu entorno» (José Miguel) e incluso cuando las cooperativas se desplazan a núcleos más grandes siguen dando dinero al pueblo del que vienen, como en la de Javi.

$Y$ es que si el territorio es una de las claves de esta comunidad, otra lo serían una serie de prácticas colectivas donde priman las relaciones de confianza, pero también de exigencia colectiva al individuo que va por libre (freerider). Javi, al hablar de cómo la dirección de la cooperativa decidía sobre destino de los excedentes del Fondo Obligatorio, nos explicó que la asamblea apoya las decisiones porque "confío y me las creo, porque tampoco voy a estar desconfiando de todo el mundo». José Miguel, socio veterano, lo expresaba al decir que en su «cooperativa se está obligando, digamos, a la gente a que vaya [a las asambleas y reuniones] y hay algunos que no van nunca» puesto que "tú tienes privilegios o tienes... por ser... y tienes obligaciones también». Este tipo de relaciones de confianza y exigencia colectiva son, en definitiva, características propias de entornos comunitaristas, como puede ser la cooperativa. Queda como premisa que esta comunidad se articula sobre el territorio como un anclaje de la identidad cooperativa.

En resumen, nosotros defendemos aquí la existencia de una identidad cooperativa vasca que articula una comunidad en el seno de cada coopera- 
tiva, pero también en el conjunto del movimiento cooperativista; y nos hemos preguntado en torno a su relación con la identidad vasca, dicha también euskaltasuna o vasquitud. También es cierto que los entrevistados son o viven en Gipuzkoa y quizás eso haya llevado a hacer un análisis parcial o tendente. Si es así, se asume como propio. Puesto que nuestro objetivo no era hablar de datos y cifras, sino de personas y sociedades y es de aquí desde donde partimos.

Para apuntalar estas conclusiones en torno a la identidad cooperativa hemos de hablar primero de la identidad vasca. Puesto que no puede haber sentimiento cooperativista "vasco» si no existe previamente algo que lo defina o excluya como «vasco» o "no vasco». Para analizar la euskaltasuna empezaremos hablando entonces de ese juego infinito de identidades superpuestas que aglutina y estructura la sociedad vasca. Que van desde el euskalki ${ }^{25}$ que cada uno habla hasta la sociedad gastronómica a la que uno pertenece pasando evidentemente por otras fronteras físicas y simbólicas como son los caseríos, los valles, los auzoak ${ }^{26}$, los pueblos, las comarcas e incluso el territorio oficial al que te adscribes. De hecho hablamos de superposición de identidades porque entre ellas no se crea un patrón excluyente sino incluyente, y frente a lo reflejado como modelo de vasquitud de los primeros estudios antropológicos se aprecia una identidad más complejizada y difícil de aprehender. Esto se debe a que;

las identidades nunca se unifican y, en los tiempos de la modernidad tardia, están cada vez más fragmentadas y fracturadas; nunca son singulares, sino construidas de múltiples maneras a través de discursos, prácticas y posiciones diferentes, a menudo cruzados y antagónicos. (Hall, 1996, p. 17)

También Kasmir dedica parte de su obra a la identidad vasca. La misma, critica que estudios coetáneos priorizaban las encuestas a las entrevistas con base a que «los vascos son reacios a tratar temas delicados con gente de fuera» (Bradley y Gelb, 1983, p. 90) en (Kasmir, 1999, p. 134). En nuestra humilde opinión, fruto de este trabajo de campo, creemos que esta afirmación que Kasmir no refuta, puede ser, cuanto menos, matizada. Entre las características particulares que tienen las relaciones interpersonales e intergrupales de la sociedad vasca podemos hablar de una que ya Arizmendiarrieta trató como parámetro necesario de su teoría sobre el personalismo: el comunitarismo. Esto es, el individuo es tal puesto que pertenece a una comunidad. $\mathrm{Y}$, no puede existir sin dicha comunidad, pero tampoco

25 Cada uno de los euskalkiak conforma una variedad dialectal del euskera.

${ }^{26}$ Auzoa puede traducirse como barrio, pero también tiene un uso habitual como vecindad. De aquí deriva la ya mencionada auzolana: trabajo comunal, trabajo vecinal. 
si esa comunidad absorbe su individualidad. El reflejo de este tipo de relaciones comunitarias se ha captado en las entrevistas. Preguntar ¿conoces a tal persona, o a tal otra? ha sido una tónica general a todas ellas, fórmula con la que el entrevistado pasaba a ser entrevistador, buscando escenarios o vínculos compartidos para crear un reconocimiento mutuo o en red. Por ejemplo, hablar de los conocidos en común dentro de las cooperativas o respecto a personas de referencia comunes en la esfera pública - la presidenta de la cooperativa, un conocido de la cuadrilla de una cooperativa, la alcaldesa de un pueblo o incluso el propio Arizmendiarrieta-. Así, esto articula una vinculación que permite, aunque sea durante un breve espacio de tiempo, entrar en esa comunidad. Por eso, las entrevistas han sido realizadas a amigos, familiares de amigos, amigos de amigos, profesores del máster o conocidos de estos, tejiendo de esta forma una red que posibilita acceder al campo de estudio. Así, matizando la cita de Kasmir, hemos observado que los términos "de aquí-de fuera» "nosotros-ellos» tienen significados muy diversos dependiendo del matiz que quiera otorgarle su hablante. Por eso, frente a la contraposición "vascos-de fuera» expresamos esa idea de identidad de otra manera, como un "dentro-fuera" de nuestra comunidad, ya sea el caserío, el pueblo o como en nuestro caso: el mundo cooperativo. Esto parece baladí pero es precisamente a lo que nos referíamos en el apartado anterior: solo son los miembros de la comunidad cooperativa los que tienen derechos respecto a esa tarea que corresponde a las cooperativas, que es la generación de empleo. Y es que como explica Hall, citando a Butler (1993 p. 22), «todas las identidades actúan por medio de la exclusión, a través de la construcción discursiva de un afuera constitutivo y la producción de sujetos abyectos y marginados (...) «la producción de un "afuera" que luego retorna para trastornar y perturbar las exclusiones prematuramente llamadas "identidades"” (Hall, 1996, p. 35). Pero entonces, ¿cómo se relaciona esa identidad vasca con la identidad cooperativa?

Durante las últimas décadas, la sociedad vasca ha venido sufriendo profundos cambios. El progresivo abandono de las zonas rurales en pos de la concentración en torno a la ciudad es una tendencia clara en todo el país, y toma diferentes expresiones en cada territorio ${ }^{27}$. Este es uno de los fac-

27 Así, en Bizkaia se van abandonando las zonas más alejadas del Gran Bilbao, que asume su estructura de polo de atracción poblacional, para acercarse a la urbe. Igualmente en Iparralde este fenómeno se da en el eje costa-interior, puesto que el llamado Agglomération Côte BasqueAdour (antes llamada BAB, por las iniciales de Baiona-Angelu-Biarritz) acumula la mayor parte de población de las comarcas norteńas. En Nafarroa, Gipuzkoa y Araba el abandono del campo es más progresivo y lento, pero el crecimiento de sus capitales y de los núcleos urbanos es imparable 
tores, no el único, de que se produzcan importantes cambios en la estructura socio-geográfica vasca. La inmigración, el problema medioambiental, los cambios culturales y religiosos, la incorporación de la mujer al trabajo asalariado, la no asunción de la responsabilidad del cuidado, la reconfiguración de los vínculos comunitarios o la llegada de la tecnología son otros de ellos.

Sabemos que los estudios que trataron la vasquitud y la cultura a finales del siglo XIX tuvieron gran repercusión e influencia, y colaboraron en reificar una identidad esencializada. Científicos como Aranzadi, Barandiarán, Caro Baroja o Eguren se sumergieron en la antropología para, según los cánones de la época, tratar de sentar con parámetros científicos qué era "lo vasco». Un sector de esa primera antropología vasca, que tanto ayudo a la conservación y difusión de parte de la cultura y al estudio de la euskaltasuna (Duvert, 2014-2015, pp. 181-183), se interesó principalmente por las tradiciones populares rurales o incluso la mitología para, en torno a una apuesta política determinada, demostrar las ancestrales raíces culturales vascas. Por eso, las actividades asociadas a un determinado entorno rural como los herri kirolak ${ }^{28}$, las propias letras del bertso ${ }^{29}$, los mercados y ferias de baserritarras $^{30}$ de cada pueblo, el mundo de la pesca ancestral (las expediciones de pesca ballenera, el remo o arraun, las cofradías de pescadores, etc.) o incluso la historia de las principales fiestas populares, han venido siendo mimadas por el imaginario vasco. A día de hoy, esa asociación como muestras de una cultura propiamente vasca puede ser complejizada con algunos apuntes críticos. El primero dirigido hacia la mirada androcéntrica con la que se construyó la base de lo que ha trascendido como identidad vasca. El segundo a tratar de pasar del valle y el baserri, o de la cofradía y el pequeño pueblo pesquero a otras perspectivas espaciales importantes en la delimitación del espacio geográfico que la sociedad vasca realiza: las de los grandes pueblos y ciudades que, aun relegadas, han influido y coexistido en las capas de esa identidad. Como ejemplo un entrevistado explicaba cuánto de alejado veía a REAS de Mondragon, situándolo, «en otra comunidad». REAS desarrolla la mayor parte de su activi-

28 Aunque el Elhuyar traduce Herri-kirol como deporte rural, la palabra en euskera engloba todo un conjunto de deportes populares vinculados con el mundo rural que aún hoy se practican y son habituales en el ocio de la sociedad vasca.

${ }^{29}$ El bertso es el arte de componer improvisadamente y recitar estrofas o versos. Sus compositores son llamados bertsolaris que muchas veces actúan entre ellos de forma dialéctica o como disputa literaria. El bertso es una tradición muy viva en la cultura vasca.

${ }^{30}$ Habitante de los caseríos o caseros. Este tipo de ferias son habituales en la mayoría de los pueblos y villas del país, en ellos los caseros bajan de sus caseríos al pueblo a vender sus productos regularmente. 
dad en Bilbo, y esa localización geográfica, la estableció como espacio alejado de su vasquitud, situada y vinculada al valle y el baserri.

Por ello, tratar de reformular ciertos postulados sobre la vasquitud y la cultura vasca es imprescindible para trabajarlo en un ámbito como las cooperativas. Se puede sumar a todo lo desarrollado, que es euskaldun todo el que habla - o «tiene», en un sentido literal- euskera, se podría definir euskaltasuna como todo aquello comprende e identifica a la comunidad euskaldun. Esta dimensión de la cultura vasca, la ha incorpora la perspectiva de Ibai Iztueta. En su obra, que no podemos reseñar enteramente, se trata la indefectible relación entre la lengua y la vasquitud. Valga una pequeña anécdota en torno a la publicación en el año 2012 que tenía por título "No entiendo ser vasca sin saber euskera», que tuvo como respuesta otra publicación de una persona no vascohablante, pero que había apostado por la educación en las ikastolas de sus hijos, que incluía un solemne «le aseguro que no es más vasca que yo» (Iztueta, 2015, p. 345). El capítulo donde se trataba tenía como título un sugerente " "Gu": Zer gara gu, nor gara?». También Kasmir trató el tema en un artículo menos conocido titulado "More Basque tan You». Tomó su título de una anécdota en que Txema, un hijo de inmigrantes integrado en el entorno cultural y político de Mondragón con su estética punk y su simpatía con la izquierda abertzale, gritó al concejal del PSE, que era un «Español!» a lo que el concejal le contestó «Más vasco que tú» (Kasmir, 2002, p. 41). El debate es tan abierto que no permite establecer categorizaciones absolutas (Iztueta, 2015, p. 348), pero si hacer esta breve reseña en torno a la relación entre el euskera y la vasquitud.

Por todo, cabría matizar cualquier definición absoluta de euskaltasuna puesto que, como cualquier identidad, esta no se construye desde la unicidad. Como puntualizaba el propio Hall «El concepto de identidad aquí desplegado no es, por lo tanto, esencialista, sino estratégico y posicional» (1996, p. 17), es decir huimos de un marco esencialista para situarnos en una identidad flexible, cambiante y abierta, que pueda ser contextual y relativa. Y todo esto nos sirve para decir que la articulación de esta comunidad se da en torno a varios ejes, donde la lengua común en la sociedad vasca, el euskera, es uno de los más importantes. Esto es así en las cooperativas, porque su promoción y fomento se pone en valor por todas las personas entrevistadas, aun cuando algunos no son vascohablantes. Además, como ya vimos el cooperativismo vasco en su conjunto tiene una relación simbiótica con el euskera, desde el ámbito de la empresa hasta el de la educación en las ikastolas. Esta puesta en valor de la normalización del euskera en el lugar de trabajo es visto como algo "casi» necesario para el desarrollo de la función social, y de una manera mucho más paradigmática que no las reminiscencias al valle y el baserri o el auzolan tan pre- 
sente en la producción sobre historia cooperativa. Y es que si analizamos la producción académica como discurso, la tendencia clara es la de asociar el mundo cooperativo con una identidad más enraizada en lo rural. La obra de MCC sobre su propia historia cooperativa dedica un apartado entero al baserri, las relaciones familiares en él y al auzolan, y no a otras características de la comunidad vasca de hoy, hablamos de «La experiencia cooperativa de Mondragon. Una síntesis general» (Altuna, 2008). Pero no es el único, también Heras-Saizarbitoria cuando cita a Caro Baroja como fuente para definir a la sociedad vasca (Heras-Saizarbitoria, 2014, p. 2) o la propia Kasmir, que al hablar del mundo rural vasco y el nacimiento de las cooperativas de Arrasate lo llega a definir como «el corazón de Euskadi» (1999, p. 98).

La cuestión que no ha podido quedar resuelta es qué vinculación tiene la identidad cooperativa con la vasquitud. Hay quien ha dicho que es una relación eminentemente política. Como Marianne Heiberg para quién esa "comunidad moral vasca», donde "el cooperativismo era el modelo de producción nacionalista vasco» (1989, p. 225) en (Kasmir, 1999, p. 127), hizo que los nacionalismos vascos apostasen por el modelo cooperativo. De hecho, esa apuesta política se dio de tal manera en algunos momentos que hay quien ha llegado a decir «que para ITÇAINA (2005), la evolución cooperativista no puede abstraerse del propio devenir político de Iparralde» (Ahedo, 2006, p. 450). Pero afirmar que esa relación política es el único vínculo es algo aventurado. Tanto en el estudio teórico como en el de campo, hay quienes acuden más a una relación sociológica en torno al cooperativismo como expresión, en el ámbito de la empresa, de la vasquitud. El propio Arizmendiarrieta y la producción discursiva de Mondragon vincula su mundo cooperativo con ciertos valores sociales asociados a esa vasquitud esencialista acotada a lo rural, hoy asociada a intelectuales como Barandiarán, aunque con algunos matices. De hecho, Sinfonia Kooperatiboa - el himno compuesto para conmemorar el 75 aniversario de la Experiencia de Mondragon- es un ejemplo paradigmático de ello. Aludir a esa cosmovisión y no a una realidad social mucho más compleja y densa es, precisamente, el reflejo de este discurso. Por último, la mayoría de los socios cooperativistas entrevistados hacen más hincapié en una relación simbólica entre las cooperativas y la identidad vasca, desde un punto de vista mucho menos complejizado, simplemente como «lo de aquí». Por ejemplo Javi nos dijo «La gente aquí sí que es un poquito fiel... Euskaltel. Si puedo coger Euskaltel en vez de Movistar, pues cojo Euskaltel... Ese sentimiento, un poco sí que existe, de lo de aquí». Ese «de aquí» puede definirse en términos de Comunidad, pero también, como Territorio vasco. Definir qué se entiende como Comunidad es tan complejo como hablar del territorio vasco y quizás no tenga una definición determinada y precisa. Dejamos 
abiertas estas cuestiones por no sobrepasar el debate de la materia cooperativa, pero sí hacer constar lo abierto de los significados.

No hemos podido establecer una relación clara entre la identidad cooperativa y la vasquitud, y quizás el vínculo entre ambas identidades sea una conjunción de todo tipo de relaciones. Lo que sí parece más claro es que ha habido grietas en esta identidad cooperativa. Como nos explicó Luís, «Estamos en un proceso de desafección identitaria. (...) Un proceso psicológico. Seguramente motivado por la tercera ola, porque ellos te dirán, dicen, es que yo vendo en China y compro no sé dónde y aquí no hay fronteras». Y es que ¿Es una filial de MCC en China parte del movimiento cooperativista vasco? ¿Tienen los trabajadores eventuales sentimiento de pertenencia al movimiento cooperativo? ¿Se da un proceso de desafección identitaria también en la sociedad vasca? Tal y como lo plantea Luís, parece que ese proceso es algo que no ha terminado y que nosotros creemos que es un proceso más amplio y complejo. Es decir, «desafección identitaria» en la sociedad y en la cooperativa. Aunque parezca baladí, esto tiene importantes consecuencias en los campos, oficinas, fábricas y lantegis del cooperativismo vasco. Mientras que José Miguel, el socio veterano hablaba de "mi cooperativa» Javi, reciente socio se refería a ella más veces como «mi empresa». Quizás esta diferencia venga produciéndose por la manera en que se transmite el cooperativismo a las nuevas generaciones de socios. José Miguel no dijo "Yo creo que la transmisión de la cooperativa... Tú antes entrabas a la cooperativa y tenías charlas y cosas que te explicaban un poquito cómo funcionaba toda la cooperativa... hoy en día, ya no» y lo achacó a que quizás "Como nuestra fábrica es más grande, ya parece que no hay tiempo para esas cosas». Otra de las ideas que surge respecto a esa desafección es la de que son los socios más jóvenes los que han perdido esos valores cooperativos. Ińaki nos dijo,

¿Qué ofrecen las cooperativas? Hasta ahora ha sido empleo y estabilidad... Pero ahora, con el reto del talento y de cómo atraer a los jóvenes, ¿qué es lo que se les ofrece? un trabajo para toda la vida. Y claro, en muchos casos, los recién licenciados o graduados, lo que menos quieren es... [risa] un trabajo para toda la vida (...). El proyecto cooperativo implica como un... compromiso.

Parece algo casual, pero teóricos del más alto nivel confirman estas sospechas. Bauman afirmó que mientras que «La principal angustia relacionada con la identidad de los tiempos modernos era la preocupación por la perdurabilidad; hoy es el interés en evitar el compromiso» (1996, p. 41). José Miguel trató un problema similar al hablar de toda su historia dentro de la cooperativa. Explicó que sus inicios habían perdido sus primeras 
aportaciones por malos resultados, que tuvieron que expulsar una dirección que quería salir del grupo y otras situaciones similares que hablaban de su procesos de resistencia en la cooperativa. Por todo, nos dijo «Pero ya te digo, lo que te estoy hablando yo, ahora es gente joven que no tiene ni idea de lo que te estoy hablando... pero ni idea. Es una pena». Lo que no conseguimos comprender es si ese conjunto de saberes que José Miguel ha ido recogiendo es una cuestión de experiencia o aquello que él llamaba "transmisión de la cooperativa", aquí llamado también como valores cooperativos e identidad. Puesto que como diría también Bauman «la identidad bien construida y duradera deja de ser un activo para convertirse en un pasivo» (1996, p. 51). Bastará ver la evolución de MCC en los próximos años para conocer si es la mera experiencia o existen fallos en la transmisión de sus valores cooperativos. Al respecto parece que Olatukoop no parece sufrir un proceso similar, si bien es cierto que su historia es más breve, en junio de 2019 alcanzaron los 5 años desde su formación mientras que el Grupo Mondragon en noviembre del 2018 celebró su 75 aniversario. En resumen, la teoría y la práctica cuestionan la erosión posmoderna al comunitarismo ${ }^{31}$. La construcción del mito del homus economicus racional y autosuficiente - que no necesita cuidados ni tiene una huella ecológica - ha ido en detrimento de los vínculos comunitarios que tan bien captó Arizmendiarrieta.

Este segundo apartado ha tratado de explicar la segunda acepción de la función social del cooperativismo analizado. Frente a la generación de empleo de calidad que exponen abiertamente los cooperativistas, existe otra función social velada o no explícita en torno a la identidad cooperativa. Así, esta construye el binomio arizmendiano de Persona-Comunidad y lo hace mediante una vinculación con el territorio donde se adscribe. Además del territorio, lo hace con el euskera mediante una ardua, y reconocida, labor para con la lengua común de Euskal Herria. Esta identidad cooperativa vinculada con la vasquitud, política, sociológica o simbólicamente, pone en valor ciertas maneras de hacer propias del comunitarismo. Incluso, yendo más allá, se puede afirmar que el hecho cooperativo requiere de un sentimiento de comunidad entre los socios cooperativistas, que nosotros solo hemos podido comprobar quebrado en situaciones de tensión política,

${ }^{31} \mathrm{Al}$ respecto hay otras voces que llegan a conclusiones parecidas. Weber, al visitar Euskal Herria, llegó a la conclusión de que "the entire structure of the country, society's uses and institutions, are strictly democratic (Weber, 2002; p. 309)» (Heras-Saizarbitoria, 2014, p. 1). Por eso, Heras-Saizarbitoria se preguntaba, "what happened to that social humus that Weber referred to during his visit to the Basque Country? The erosion of such soil would appear more evident in the individualization process of the post-modern globalized society and would seem to affect alternative organizational forms such as Mondragon more greatly.» (2014, p. 12). 
económica o social como la Huelga de Ulgor de 1974 o la propia caída de Fagor Electrodomésticos. También se ha detectado un proceso de desafección identitaria en torno a las cooperativas vascas, al menos las agrupadas en torno a MCC. Quizás podemos compararlo con el proceso de resignificación identitaria en la propia sociedad vasca que trata de redefinirse incorporando nuevas demandas sociales, pero de una manera diferente. Hay una cita de Arizmendiarrieta que nos habla de los dos apartados de este capítulo, trabajo e identidad: "Es el trabajo el que hace a los hombres y a los pueblos $^{32}$ » (Azurmendi 2000, n/c) en (Altuna, 2008, p. 72). Esta cita resume bien cuál puede ser el camino para reafirmar y apuntalar la sólida identidad cooperativa vasca. Repensar la estrategia en el exterior y afianzar los proyectos en torno a la educación de los socios y la transmisión de los valores cooperativos para seguir configurando un modelo de empresa apto para la realidad social de Euskal Herria: la cooperativa.

\subsection{Discusión sobre la materia: análisis del discurso académico}

Como último apartado del trabajo de campo, analizaremos ahora qué dice el discurso académico sobre los temas aquí expuestos. Y para ser más concretos, trabajaremos la producción textual de Mondragon y de algunos académicos externos en sus más recientes trabajos. Y empezaremos por uno de los temas más tratados con más frecuencia por la literatura académica: la internacionalización del Grupo Mondragon. El discurso cooperativo, los diferentes artículos académicos y los propios entrevistados suelen apuntar a la internacionalización y los cambios productivos de los años 90's como un «mal necesario», es decir, políticas objetivamente negativas pero necesarias para la marcha económica de las cooperativas. Explicado en palabras de Ińaki, investigador entrevistado «la lectura que se hace de la internacionalización de Mondragon es un poco... también crear plantas en el exterior ha sido necesario para mantener el empleo aquí». Esta premisa parece ser otro topoi del discurso cooperativista mondragonés.

El modelo de internacionalización elegido por las cooperativas de MCC ha sido el de empresas matrices cooperativas que dominaban a las sociedades capitalistas filiales sin dejar espacio a posibles federaciones o

\footnotetext{
32 Se podría debatir qué entendemos aquí por pueblos, si cada uno de los núcleos de población o cada una de las comunidades con una identidad. Sería fácil de disolver la dicotomía, si es que existe, entre pueblo y país mediante el uso de la palabra en euskera: Herria. Así, el mismo Elhuyar traduce Herri en un sentido de pueblo pero también como país. En inglés, como people y como nation. En todo caso, puede decirse que Herri tiene ese valor polisémica de pueblo, país, e incluso nación.
} 
modelos de cooperación, cosa que ha sido definida como «división internacional de trabajo» (Errasti 2013, p. 54). En este proceso "la pérdida de actividad y de empleo se está produciendo con el menor coste social posible, tanto en las plantas cooperativas como en las plantas de las filiales europeas" pero también se dice que "el carácter cooperativo de la matriz y el objetivo de defensa a ultranza de los puestos de trabajo de los socios puede condicionar el desarrollo de las plantas filiales y sus trabajadores» (Errasti 2013, pp. 55-54). Sin entrar al detalle sobre las causas y consecuencias de la internacionalización, sí queremos poner en contraste este proceso con cambios surgidos en la identidad cooperativa de la que hemos hablado.

En 2002, hubo quien advirtió de algunos riesgos derivados de la salida a los países de la periferia capitalista. Se dijo que en «la situación actual existe un problema de identidad en aquellas cooperativas con filiales en el extranjero» cosa que llevaba «a replantear las relaciones entre trabajo y capital, no sólo en la periferia, sino también en el centro cooperativo" (Errasti et al., 2002, p. 140). Pero para más inri, en el zenit de este proceso, el propio presidente del Consejo General de MCC, Antonio Cancelo, escribió un artículo en la revista TU Lankide titulado «Globalización y señas de identidad». Cancelo justificó la internacionalización diciendo que «el entorno económico nos viene dado» (2000, p. 20). Además, en el mismo artículo trataba de abordar dos cuestiones: las "condiciones de trabajo en las empresas no cooperativas» y «el compromiso socioeconómico de las implantaciones exteriores» (Cancelo 2000, p. 21). Esto era, para él, traducir la internacionalización en una serie de prácticas que diferenciasen a las cooperativas de otras empresas de capital, manteniendo estas señas de identidad cooperativa pero atendiendo a los objetivos de la internacionalización, lo que fue denominado como modelo finalista. En todo caso, hoy, 20 años después de esas palabras, poco saben los cooperativistas de esos objetivos ideales. De hecho, cuando Javi nos habló de «su visión» hizo expresa mención a las filiales puesto que dentro de su cooperativa tiene asignadas tareas que requieren visitarlas. Al ser preguntado por las condiciones de los trabajadores afirmó que las condiciones de los trabajadores de las filiales no son las mismas «aunque se intenta que sea... más o menos justo». Él reconocía que montar una empresa en la India se hacía por ahorrar costes en la mano de obra y que, por tanto, no «van a cobrar lo mismo que aquí». Además dijo «No vamos a ser tampoco hipócritas, las cosas como son. Obviamente no disfrutan de todos los beneficios que tengamos que tener nosotros. Porque no son cooperativistas». Por contra, Iñaki, investigador y socio cooperativista, reconocía abiertamente esas críticas pero las consideraba infundadas debido a las dificultades culturales de cooperativizar producciones en filiales así como de asumir el riesgo de la pérdida de soberanía. 
En todo caso, parece que la internacionalización siguió su curso y que siguieron primando los objetivos financieros a los de la transformación social por causa del empleo. "Algunos lo denominan «neocooperativismo", porque la nueva perspectiva estratégica trata de aunar el posibilismo y la identidad (Larrañaga, 1996). Otros "coopitalismo", toda vez que combina sociedades cooperativas y de capital (Defourny, 1999)" (Errasti et al., 2002, p. 139). Siendo "coopitalismo» el término con mayor seguimiento en la académica, creemos, además, que refleja bien el mantenimiento de la estructura cooperativa interna junto con las prácticas capitalistas externas. Aunque pueda haber otras justificaciones, queda claro que una de las causas por las que Mondragon no haya realizado una política inclusiva con las filiales es, simple y llanamente, su interés en el mantenimiento del empleo de los socios y, por tanto, de la competitividad necesaria para ello. Lo ratifican las conclusiones de Bretos y Errasti cuando dicen que «las cooperativas de Mondragon se internacionalizan con el objetivo de mantener su competitividad y proteger los puestos de trabajo de los socios trabajadores en las plantas vascas» lo ha conseguido porque «ejercen un elevado control centralizado sobre las filiales, reteniendo los recursos estratégicos y procesos de alto valor añadido" (2018, p. 64). Esto no oculta notables logros sociales en determinados países - como Brasil o México- pese a los no escasos problemas jurídicos y sociológicos que generan la cooperativización de las filiales.

Una vez vista la evolución económica de la internacionalización del Grupo Mondragon hemos de comprobar qué afectación ha tenido a la identidad cooperativa y si esta se ha mantenido, como defendía el presidente de MCC en el año 2000. De hecho cuando Fagor tuvo que afrontar la compra de Brandt, resurgieron los debates y discusiones asociados al mantenimiento de la identidad cooperativa y el carácter multinacional de la empresa. La decisión al respecto fue la misma que para las filiales «integrar los nuevos negocios y empresas participadas de una forma más acorde con los principios y valores de MCC, sin que esto signifique transformar las sociedades anónimas en cooperativas» (Mendizabal et al., 2005, p. 261). Ahora bien, es en este momento cuando empiezan a observarse ciertos problemas. Los mismo autores dirán;

se constata que como consecuencia de las operaciones de compra y constitución de filiales la identidad cooperativa ha quedado profundamente alterada en el conjunto de Grupo Fagor. Los socios cooperativos de Fagor se han convertido en una forma de empresarios capitalistas, y la posibilidad de crear una nueva forma de empresa multinacional cooperativa, o más democrática que la actual, no se vislumbra en el horizonte, aunque como hemos visto si existe cierta preocupación al respecto. (Mendizabal et al., 2005, p. 261) 
«La identidad cooperativa ha quedado profundamente alterada». Mondragon venía sufriendo a causa de su internalización una erosión constante en torno a su proyecto cooperativo pero no tomó cartas en el asunto. La academia y la propia producción escrita de MCC advirtió ya de ese proceso que aquí hemos llamado de "desafección identitaria». Este proceso vino acompañado de la creación de un «nosotros» sobre el que se construye la identidad cooperativa limitado a los socios cooperativistas y no al resto de la plantilla, ya en los centros matrices o en las filiales. Con esto, podemos construir una importante conclusión y es que la distinción de Kasmir, o de Ordaindu, de «los de arriba» y «los de abajo» no es el principal vector de construcción de identidad en Mondragon.

Todos estos cambios en la identidad cooperativa no han sido suficientemente trabajados desde el cooperativismo de Mondragon, al menos públicamente, pero tampoco desde la Academia. En Mondragon no hemos hallado una reformulación de los valores en torno al trabajo cooperativo, por lo que no se puede afirmar que haya visos de cambios. Quizás sea Olatukoop la que actúe de revulsivo para MCC y transicione hacia un cuarto ciclo donde la identidad cooperativa sea un valor relevante. Los mismos autores ya reconocían que «en el contexto de las cooperativas industriales el debate reside en cómo pueden adaptarse a esta nueva situación sin perder sus seńas de identidad, que básicamente se refieren al mantenimiento de las empresas enraizadas en la comunidad en un modelo de empresa democrático" (Mendizabal et al., 2005, p. 262).

$Y$ si bien es cierto que el con el concurso de acreedores de FED se generó un impacto que aún hoy es una herida abierta, no es menos cierto que la doctrina es casi unánime en que «una vez pasado ese desconcierto inicial, debe plantearse el caso Fagor como una oportunidad para reflexionar sobre el modelo de corporación que debe seguir MCC» (Alustiza, 2015, p. 337). $\mathrm{Al}$ respecto, huelga decir que, en no pocas ocasiones, la producción académica en torno al cooperativismo vasco se muestra indulgente en torno a una evidente dejadez de la superestructura cooperativa mondragonesa respecto a los repetidos intentos internos para retomar cierto impuso cooperativo. Ellos mismo reconocen la existencia de dos «almas»;

Una que manifiesta una sensación de cierta pérdida de vitalidad del cooperativismo de Mondragon, al que se percibe cada vez más encerrado en si mismo $y$ a cada cooperativa en su propio mundo "peleando por el margen", y con la ambición mermada para plantear nuevos caminos que le permitan conectar con los deseos y demandas emergentes de un orden social más justo y humano (...) Frente a ello, desde una segunda perspectiva se asume el carácter más conservador de MONDRAGON respecto al impulso de los origenes, pero lo atribuye al periodo de maduración propio de las organizaciones consolidadas" $Y$ conserva- 
dor no peyorativamente puesto que, como demuestra la crisis de FAGOR, «el solo hecho de conservar lo ya constituido no es poco reto en estos escenarios económicos tan convulsos y competitivos». (Ortega y Uriarte, 2015, p. 10)

Estas dos almas, tendencias o perspectivas en el seno de Mondragon no son exclusivas de la Corporación, en general, en el seno del movimiento cooperativista vasco vemos cierta tensión entre el posibilismo y el idealismo. De una forma más "poética», si se nos permite, y sin abandonar propiamente el análisis crítico de discurso, podemos parafrasear el estribillo de la ya mencionada Sinfonia Kooperatiboa. Este estribillo es también el subtítulo de nuestro trabajo "Hanka bat lurrean, beste bat airean ${ }^{33}$ ", puesto que esta tensión entre lo económico y la identidad se refleja también en el cooperativismo de anteguerra, en el propio desarrollo de las cooperativas del Grupo Mondragon y en la dialéctica entre Olatukoop y la actual MCC. Creemos que lograr crear una tensión constructiva en torno al seno del movimiento cooperativista, pero también con la sociedad vasca, es algo necesario e ineludible. En Mondragon esas dos almas «coinciden en la necesidad de dotar de un mayor impulso al principio de la transformación social» para que la Experiencia cooperativa "conecte con las emergentes aspiraciones humanas, dote de un revitalizado sentido al proyecto, y proyecte la imagen de MONDRAGON (quizá un tanto escorada hacia el imaginario de lo empresarial) como una experiencia interesante en el proceso de emancipación social» (Ortega y Uriarte, 2015, p. 10).

Para el cooperativismo de Mondragon, la tecnificación y la reestructuración empresarial interna fueron clave para su crecimiento, pero también trajeron profundos cambios en la conciencia de las personas socias cooperativistas. La internacionalización fue el golpe de gracia a estos procesos, como seńalan los autores reseñados. Estos vienen advirtiendo de estos procesos de desafección desde hace tiempo pero mediante ciertos tonos discursivos que, conscientes de estas prácticas posibilistas, siguen alabando las virtudes de un Grupo que parece no oír las críticas. Los socios cooperativistas expresan esto como "hipocresía» mientras que doctrinalmente se ha llamado "coopitalismo». La esperanza por tanto, se halla de nuevo en la masa social que componen las cooperativas, pero con dos notables diferencias. En primer lugar, los efectos de la caída de Fagor en el seno de los cooperativistas es todavía un asunto abierto. La segunda, es la que se refiere a la existencia de un cooperativismo alternativo con

33 «Una pierna en la tierra, otra en el aire». A modo anecdótico, cabe mencionar que la carga simbólica de la frase en euskera es todavía mayor, puesto que se puede entender como una referencia poética al tradicional baile del aurresku donde el dantzari realiza movimientos alternos elevando una pierna al aire mientras la otra se dirige al suelo. 
voluntad de hegemonía que puede hacer que se acabe con la «indulgencia de la Academia» al provocar que su mirada se desplace hacia otra propuesta política. Corresponde al propio movimiento definir su papel en torno a este nuevo ciclo histórico para poner en el centro el proyecto de emancipación social, retomando el proyecto de Arizmendiarrieta o trazando una nueva senda.

\section{Conclusiones}

El objetivo del trabajo era responder a una pregunta aparentemente sencilla ¿Cuál es la función social de las cooperativas vascas? Antes de entrar a las conclusiones, debemos realizar un apunte sobre los límites de un trabajo de este tipo. El cooperativismo vasco ha sido, y es, un movimiento complejo, dinámico y poliédrico que bebe de numerosas fuentes teóricas y prácticas. Esto hace necesario un trabajo en profundidad en su historia puesto que esta, es también parte de la historia de Euskal Herria. Esta parte del trabajo tiene un gran potencial para investigando, no solo porque apenas se ha sintetizado y construido una historia del cooperativismo vasco, sino por el notable interés de diferentes actores del movimiento, como Olatukoop, la MU o incluso el Gobierno Vasco, en torno a la creación de lo que ellos llaman «relato cooperativo». De lo que nazca de este relato dependerá en gran medida el futuro, y el pasado, del cooperativismo vasco.

Además, para ello, es imprescindible sacar a la luz la Historia olvidada y minorizada. Como la del papel de la mujer, puesto que su participación ha sido invisibilizada y silenciada también en el cooperativismo. En el trabajo de campo, no hemos incluido la voz de la mujer en las cooperativas, cosa que asumimos como crítica. Tampoco hemos contado con alguna voz del cooperativismo no asociado o de trabajadores no socios, para incluir aquellas perspectivas tantas veces olvidadas. $\mathrm{Y}$ es que el peso del cooperativismo industrial en el conjunto del movimiento es, aún hoy, un eje que centra y lastra la construcción de una historia cooperativa más completa. El cooperativismo agrario, las cooperativas de consumo, las ikastolas o las cooperativas de vivienda, presente en los siete territorios son algunos de los momentos excluidos de ciertos relatos en torno al movimiento que consideramos inseparables del mismo. En todo caso, huir de visiones «mondragocéntricas» es interesante y provechoso, pero tiene que hacerse en su justa medida debido al peso de la corporación en el conjunto del sector. En todo caso, creemos haber tratado con el máximo rigor las entrevistas y evitado ofrecer afirmaciones categóricas durante su tratamiento, obviando posibles visiones particulares o sesgadas, siempre teniendo presente que la mera se- 
lección ya es un sesgo. Ahora, pasamos a sintetizar nuestras respuestas a la pregunta de investigación.

Partimos de una premisa básica que actúa como conclusión principal. La función social de las cooperativas vascas es en términos de discurso - y de práctica - la generación de empleo de calidad arraigado al territorio. Esto es una realidad con unas profundas raíces, tanto a nivel histórico como sociológico. Las cooperativas son el motor laboral en numerosas áreas del territorio vasco cumpliendo así con los objetivos de los que partía el cooperativismo. Sin embargo, frente a ese discurso hegemónico existen numerosos matices. Aquellos más importantes son los relacionados con la viabilidad económica y la de «los otros» cooperativos; las personas no socias. Sobre el primer matiz, y con una mirada puesta en la reciente caída de Fagor, se ha constatado que la tarea de generar empleo de calidad está subyugada necesariamente a la viabilidad de la empresa y, al menos en Mondragon, esta es una idea generalizada por los socios. Por otro lado, la existencia de diferentes categorías de trabajadores no socios en las matrices y en las filiales es una idea que, aunque no parezca tensionar a los socios, se tiene presente como crítica. La importancia de estas tensiones es notable, la cooperativa se crea como asociación de iguales con el objetivo de satisfacer una necesidad común, por ello, alterar estas premisas es atacar a la idea básica de cooperativa. La delimitación de estas sociedades como comunidades simbólicas que son, hace que la garantía última de la función social sea el propio trabajo cooperativo digno y arraigado a la Comunidad. En Euskal Herria, esa comunidad es indefectiblemente una comunidad-territorio, de ahí que la recomarcalización sea algo tan asumido en el cuarto ciclo. Además, la visión de este nuevo ciclo respecto a los trabajos invisibles o la huella ecológica pueden ser importantes revulsivos respecto a la formulación de nuevos modelos cooperativos. Una dialéctica entre sectores de Mondragon en la que interviene también la agrupación Olatukoop. Habrá que atender al avance y a la capacidad del movimiento de generar entre ellos suficientes espacios de encuentro.

Pero no es la única reflexión alcanzada durante el trabajo. Así, hemos podido entrever que existe otra función social. Las sociedades cooperativas son, dentro del derecho y la economía, sociedades muy particulares y hay quien piensa que sus cargas contables y de gestión hagan poco idónea su elección, en el caso de Euskal Herria no podemos afirmar esto. Y esto es así porque existe una fuerte identidad cooperativa en torno a estas sociedades. Esta identidad cooperativa, que trasciende a otras agrupaciones como MCC u Olatukoop, tiene como punto de referencia el territorio y por eso su estudio es tan interesante. La relación triple de Persona-Comunidad cooperativa-Territorio es central, esto hace que si se modifican los límites o espacios de alguno de estos elementos cambie también el marco de iden- 
tidad asociado. Hay quien ha vinculado esta relación a la misma vasquitud, tratando de argumentar que el cooperativismo es, sociológicamente, la forma de producción de los vascos. Pero hay también quien dice que esta relación es eminentemente política. Nosotros, de los socios cooperativistas, tan solo hemos podido comprobar que la asociación se hace de una manera simbólica, como "lo de aquí»; por lo que extender nuestras conclusiones más allá sería harto arriesgado.

Por otro lado, si queremos hablar de un Cooperativismo vasco, hemos de tener claro qué abarca cada término. Por un lado, para el movimiento cooperativo tan solo las personas socias alcanzan el «adentro» constitutivo de la comunidad cooperativa dejando de lado a otras personas que también forman parte de la misma. De otro lado, para que exista un cooperativismo vasco han de sentarse las bases de qué es vasco. Precisamente estos es lo que viene a colmar la euskaltasuna. Y aunque el concepto de vasquitud es objeto de un debate en construcción, las opciones sobre las que edificarla pasan desde las referencias a tiempos inmemoriales hasta la lengua común al país Es necesario, pues, decir que ambas comunidades e identidades no pueden ser definidas en términos absolutos o cerrados, de ahí, que los procesos de construcción y articulación sean tan provechosos al estudio.

Por último, cabe decir que la producción académica al respecto viene señalando estos procesos desde hace varias décadas. Los problemas asociados a la internacionalización y a la existencia de una masa de trabajadores y trabajadoras no asociados han generado numerosos problemas en la definición de una identidad cooperativa. Frente a ello, MCC no parece haber asumido y trabajado con diligencia las críticas y la reformulación del nuevo ciclo no parece algo prioritario dentro de la corporación. Sin embargo, hay motivos para la esperanza. La caída de Fagor ha supuesto un serio toque de atención a Mondragon. Adicionalmente, la creación de Olatukoop ha hecho nacer una disputa discursiva y simbólica en torno al "qué deben ser» las cooperativas vascas que mantendrá vivo el debate. Volvemos a esa tensión dialéctica y constructiva de lo pragmático y lo idealista, de los proyectos centrales y las alternativas autosuficientes, de la centralidad del mercado y la transformación social, en suma del Hanka bat lurrean, beste bat airean.

Igualmente durante el transcurso del trabajo, hemos atendido a la existencia de un proceso de pérdida o desgaste de esa identidad cooperativa, la desafección identitaria, cuyo origen puede estar causado en los procesos sociológicos de transformación de la sociedad vasca o en la propia transmisión cooperativa a las nuevas generaciones de personas socias. La academia parece coincidir en estos procesos de pérdida o desestructuración de la identidad en las sociedades posmodernas. Bauman lo sintetizó diciendo que mientras que «La modernidad construía en acero y hor- 
migón; la posmodernidad construye en plástico biodegradable» (Bauman, 1996 , p. 41). Esto es lo que hace que los procesos de construcción de identidad o de resistencia de esas identidades sean tan complejos. La desafección es la piedra angular de los procesos de reconstitución de identidades dentro de las cooperativas, y por ello, tratar de sostener una identidad tan sólida como la del socio o socia cooperativista vasco en nuestros tiempos es una tarea hercúlea. Consideramos que este tema no se ha estudiado suficientemente en el seno de los estudios cooperativos y, cuando se ha trabajado, lo ha sido siempre de una manera superficial. Quizás por esto - y no por la viabilidad económica — es que puede quebrar el sólido cooperativismo industrial vasco. Es, en definitiva, el gran reto del cooperativismo en Euskal Herria.

Frente a esa desafección identitaria existe una posibilidad que se reencuentra con Arizmendiarrieta cuando decía que «es el trabajo el que hace a los hombres y a los pueblos» (Azurmendi 2000, n/c) en (Altuna, 2008, p. 72). En nuestra opinión, las soluciones pasan por hacer que la comunidad a la que alcanza la función social se amplíe o, por reducir la distancia entre los socios cooperativistas y el resto de las plantilla "de aquí» $\mathrm{y}$ "de fuera». Si las cooperativas tienen como tarea social generar empleo de calidad y con un fuerte arraigo territorial, es de justicia que sea la sociedad la que les exija ampliar su comunidad y posibilitar a otros grupos que trabajan en las cooperativas las mismas condiciones, que como ya dijimos, son las condiciones acordes a la dignidad humana, o como dirían en MCC, Humanity at work. En todo caso, hay que decir que, durante la historia del cooperativismo aquí analizada, las sociedades cooperativas y sus socios han estado a la altura de las circunstancias. La generación de empleo y la distribución de riqueza son una realidad gracias a las cooperativas y quizás tan solo sea necesario transicionar todas estas estructuras hacia el cuarto ciclo cooperativo, con una mirada puesta en todas las comarcas de los siete territorios, en la cuestión medioambiental, en el trabajo visible e invisible de las mujeres y en incorporar la perspectiva de género. En Olatukoop estos paradigmas parecen claros, pero su tamaño les limita para llegar discursivamente a los propios socios del resto de cooperativas; en MCC es también su tamaño el que le limita para realizar profundos cambios que parte de su masa social está demandando con cada vez mayor intensidad. Quizás sea la combinación de ambos lo que permita cerrar etapas demasiado escoradas hacia lo empresarial y superar escollos como la caída de Fagor.

Reformulando la cita de Arizmendiarrieta, podemos decir que el trabajo hace a las personas y a los pueblos y es aquí donde las Cooperativas en Euskal Herria tienen una función social histórica, en proveer al pueblo vasco de trabajo de calidad y a las personas de un arraigo con su 
territorio - una parte imprescindible del bizigarritasuna o la "vida vivible»- de tal manera que el necesario vínculo entre ambos sea la identidad cooperativa.

\section{Bibliografía}

Ahedo, I. (2006). El viaje de la identidad y el nacionalismo vasco en Iparralde (1789-2005) (Vol. II). Vitoria-Gasteiz: Eusko Jaurlaritzaren Argitalpen Zerbitzu Nagusia/ Servicio Central de Publicaciones del Gobierno Vasco.

Alcaide, J. (2007). Evolución de la población española en el siglo XX, por provincias y Comunidades Autónomas (Vol. I). Bilbao: Fundación BBVA.

Altuna, L.G. (2008). La experiencia cooperativa de Mondragon. Una sintesis general. Eskoriatza: Lanki, Instituto de Estudios Cooperativos.

Alustiza, A. (2015). El impacto de la crisis de Fagor en el cooperativismo vasco. Boletín de la Asociación Internacional de Derecho Cooperativo (49), 321-338.

Arizmendiarrieta, J. (2 de abril de 1970). "Las Mujeres en la Experiencia Cooperativa de Mondragón» Constitución de la entidad cooperativa de Auzo-Lagun Auzo-Lagun, S.Coop. y la mujer, 00 - Sin serie (Auzo-Lagun, Caja 78, Clave 18101, Signatura 78.32.12), Fondo Documental Arizmendiarrieta. Auñamendia Eusko Ikaskuntza.

Arrieta, L., Barandiaran, M., Mujika, A., y Rodríguez, J.A. (1998). El movimiento cooperativo en Euskadi: 1884-1938. Fundación Sabino Arana Kultur Elkargoa.

Auzo Lagun. (2015). Quiénes somos [online], obtenido en https://www.auzolagun. com/nosotros-2/

Azurmendi, J. (1992). El Hombre Cooperativo. Pensamiento de Arizmendiarrieta. Olatora: Azatza, S.A.

Azurmendi, J. (2000). Pensadores vascos: José María Arizmendiarrieta. Cursos de verano de la UPV/EHU.

Basterretxea, I., Heras-Saizarbitoria, I., y Lertxundi, A. (2019). Can employee ownership and human resource management policies clash in worker cooperatives? Lessons from a defunct cooperative. Human Resource Management.

Bauman, Z. (1996). De peregrino a turista, o una breve historia de la identidad. En S. Hall, y P. du Gay, Cuestiones de identidad cultural (pp. 40-68). Buenos Aires: Amorrortu.

Bengoetxea, A. (2016). Las Cooperativas. CIRIEC-España, Revista de Economía Pública, Social y Cooperativa, 29, 205-234.

Bradley, K., y Gelb, A. (1983). Cooperation at work: The Mondragon Experiencie. Londres: Heinemann.

Bretos, I., y Errasti, A. (2018). La transmisión de los valores y prácticas organizacionales cooperativas en las filiales extranjeras: El caso de la cooperativa mul- 
tinacional Fagor Ederlan. REVESCO. Revista de Estudios Cooperativos, 127, 45-69.

Butler. J. (1993). Bodies That Matter. Londres: Routledge.

Cancelo, A. (2000). Globalización y señas de identidad. TU Lankide, 20-21.

Cassirer, E. (1985). El mito del Estado. México D.F.: Fondo de Cultura Económica.

Defourny, J. (1999). L'économie social au Nord et au Sud, Paris: Jalons, De Boeck.

Duvert, M. (2014-2015). José Miguel de Barandiaran y la investigación antropológica en el País Vasco (1936 a 1953). Cuadernos de Etnología y Etnografía de Navarra (CEEN),89, 179-201.

Errasti, A. (2013). Tensiones y oportunidades en las multinacionales coopitalistas de Mondragón: El caso de Fagor Sdad. Coop. REVESCO, Revista de Estudios Cooperativos (113 - Monográfico: Crisis económica actual y sus posibles), 30-60.

Errasti, A. M., Heras-Saizarbitoria, I., Elgoibar, P. y Begiristain, A. (2002). La internacionalización de las cooperativas y su responsabilidad social. Revista de Dirección y Administración de empresas / Empresu Zuzendaritza eta Administraziorako Aldizkaria, 10, 119-145.

Estornés, I., y Garmendia, J. (2020). Auzolan. Enciclopedia Auñamendi [online], obtenido en http://aunamendi.eusko-ikaskuntza.eus/es/auzolan/ar-16620/

ETA (1981). Documento. Donostia: Editorial Lur.

Euskal Estatistika Erakundea/Instituto Vasco de Estadística (2008 (act. 2017)). PIB de la C.A. de Euskadi por territorio histórico. Precios corrientes (miles euros y tasa variación). 1980-2017(a). Euskadiko Jaularitza/ Gobierno de Euskadi.

Fici, A. (2015). La función social de las cooperativas: Notas de Derecho comparado. REVESCO. Revista de Estudios Cooperativos, 117, 77-98.

Hall, S. (1996). Introducción: ¿quién necesita «identidad»? En S. Hall, y P. du Gay, Cuestiones de identidad cultural (pp. 13-39). Buenos Aires: Amorrortu.

Heiberg, M. (1980). Basques, Anti-Basques and the Moral Community. En R.D. Grillo, "Nation" and "State» in Europe: Anthropological Perspectives (pp. 45-61). New York: Praeger.

Heiberg, M. (1989). The Making of the Basque Nation. Cambridge: Cambridge University Press.

Hemen Elkartea. (2017). Hemen Elkartea; Historique [online], obtenido en http:// hemen-herrikoa.org/hemen/

Heras-Saizarbitoria, I. (2014). The Ties that Bind? Exploring the Organizational Principles of Workers' Owned Organizations in Practice. Organization, 21, 645-665.

Itçaina, X. (2005). L'Identité au travail. Economie sociale et solidaire et mouvement identitaire en Pays Basque. First European conference of the tirad-sector research and the EMES european research network. Paris: Abril, 27-29 CNAM.

Itçaina, X. (2010). Les régimes territoriaux de l'économie sociale et solidaire: le cas du Pays Basque français. Géographie, économie, société, 12 (1), 71-87.

Iztueta, I. (2015). Cultura Vasca vs. Euskal Kultura. Donostia: Utriusque Vasconiae. 
Kasmir, S. (1999). El mito de Mondragón (Cooperativas, politica y clase trabajadora en una ciudad del País Vasco) (1. ${ }^{\mathrm{a}}$ ed.). Tafalla: Txalaparta.

Kasmir, S. (2002). "More Basque tan You» Class, Youth and Identity in an Industrial Basque Town. Identities: Global Studies in Culture and Power, 9, 39-68.

Kasmir, S. (2016). The Mondragon Cooperatives and Global Capitalism: A Critical Analysis. New Labour Forum, 25 (Vol. I), 52-59.

Larrańaga, J. (1998): El Cooperativismo de Mondragón. Interioridades de una utopia, Aretxabaleta: Azatza (Olatora).

Lertxundi, J. (2002). La tecnocracia en MCC, el Opus Dei y el PNV: (la historia jamás contada). Donostia: Basandere Argitalexea.

Lezamiz, M. (s.f.). Relato breve del cooperativismo. Aretxabaleta: Olatora, Obra Social de la Caja Laboral.

Martín Rojo, L. (2014). El análisis crítico del discurso. Fronteras y exclusión social en los discursos racistas. En L. Iñiguez, Análisis del discurso. Manual para las ciencias sociales (pp. 157-201) España: Editorial UOC.

Mendizabal, A., Begiristain, A. y Errasti, A. (2005). Deslocalizaciones y empleo cooperativo. El caso de Fagor Electrodomésticos S. Coop. CIRIEC-España, Revista de Economía Pública, Social y Cooperativa, 52: 237-266.

Monzón, J.L. (2003). El cooperativismo en la historia de la literatura económica. CIRIEC-España, Revista de Economía Pública, Social y Cooperativa, 44, 9-32.

Olábarri, I. (1985). Tradiciones cooperativas vascas. En J. Intxausti (ed.), Euskal Herria. Historia y sociedad (pp. 279-307). Donostia: Caja Laboral Popular-Lan Kide Aurrezkia.

Ordaindu elkartea. (2019). Estudio de la UPV sobre las causas de la caída de FAGOR Electrodomésticos [online], obtenido en http://ordaindu.blogspot. com/2019/05/estudio-de-la-upv-sobre-las-causas-de.html

Ortega, I. y Uriarte, L. (2015). Retos y dilemas del Cooperativismo de Mondragón. Tras la Caída de Fagor Electrodomésticos. Cuadernos de Lanki (10), $1-45$.

Roussell, C., y Albóniga, N. (1994). Historia de las cooperativas de consumo vascas. Vitoria-Gasteiz: Euskadiko Kontsumo Kooperatiben Federazioa/ Confederación de Cooperativas de Consumo de Euskadi.

Saéz, J. (1978). Cooperativas de consumo y economatos su situación en el mercado a comienzos de 1976: breve análisis estadístico. Estudios cooperativos, 44, 33-54.

Salvador, A.R. (1988). La Caja Agrícola de Tafalla. Primera Caja rural de Navarra. 1902. Principe de Viana. Anejo, 10, 425-434.

TU Lankide (2019). Ausolan, 50 años de cooperativismo impulsado por 17 mujeres inconformistas [online], https:/www.tulankide.com/es/ausolan-50-anos-decooperativismo-impulsado-por-17-mujeres-decididas-e-inconformistas

Weber, M. (2002). Dos cartas sobre el País Vasco. Revista Española de Investigaciones Sociológicas, 100/02, 300-314.

Yoldi, A. (1916). El movimiento Social Agrario en Navarra. Semana Social de España: Sexto Curso. 